\title{
Atmospheric oxidation of 1,3-butadiene: characterization of gas and aerosol reaction products and implications for $\mathbf{P M}_{2.5}$
}

\author{
M. Jaoui ${ }^{1}$, M. Lewandowski ${ }^{2}$, K. Docherty ${ }^{1}$, J. H. Offenberg ${ }^{2}$, and T. E. Kleindienst ${ }^{2}$ \\ ${ }^{1}$ Alion Science and Technology, P.O. Box 12313, Research Triangle Park, NC 27709, USA \\ ${ }^{2}$ US Environmental Protection Agency, Office of Research and Development, \\ National Exposure Research Laboratory, Research Triangle Park, NC 27711, USA
}

Correspondence to: M. Jaoui (jaoui.mohammed@epa.gov)

Received: 21 April 2014 - Published in Atmos. Chem. Phys. Discuss.: 2 June 2014

Revised: 9 September 2014 - Accepted: 1 October 2014 - Published: 20 December 2014

\begin{abstract}
Secondary organic aerosol (SOA) was generated by irradiating 1,3-butadiene (13BD) in the presence of $\mathrm{H}_{2} \mathrm{O}_{2}$ or $\mathrm{NO}_{\mathrm{x}}$. Experiments were conducted in a smog chamber operated in either flow or batch mode. A filter/denuder sampling system was used for simultaneously collecting gasand particle-phase products. The chemical composition of the gas phase and SOA was analyzed using derivativebased methods (BSTFA, BSTFA + PFBHA, or DNPH) followed by gas chromatography-mass spectrometry (GCMS) or high-performance liquid chromatography (HPLC) analysis of the derivative compounds. The analysis showed the occurrence of more than 60 oxygenated organic compounds in the gas and particle phases, of which 31 organic monomers were tentatively identified. The major identified products include glyceric acid, $d$-threitol, erythritol, $d$ threonic acid, meso-threonic acid, erythrose, malic acid, tartaric acid, and carbonyls including glycolaldehyde, glyoxal, acrolein, malonaldehyde, glyceraldehyde, and peroxyacryloyl nitrate (APAN). Some of these were detected in ambient $\mathrm{PM}_{2.5}$ samples, and could potentially serve as organic markers of 13BD. Furthermore, a series of oligoesters were detected and found to be produced through chemical reactions occurring in the aerosol phase between compounds bearing alcoholic groups and compounds bearing acidic groups.

SOA was analyzed for organic mass to organic carbon $(\mathrm{OM} / \mathrm{OC})$ ratio, effective enthalpy of vaporization $\left(\Delta H_{\text {vap }}^{\mathrm{eff}}\right)$, and aerosol yield. The average OM / OC ratio and SOA density were $2.7 \pm 0.09$ and $1.2 \pm 0.05$, respectively. The average $\Delta H_{\text {vap }}^{\text {eff }}$ was $-26.08 \pm 1.46 \mathrm{~kJ} \mathrm{~mol}^{-1}$, a value lower than that of isoprene SOA. The average laboratory SOA yield measured in this study at aerosol mass concentrations be-
\end{abstract}

tween 22.5 and $140.2 \mu \mathrm{g} \mathrm{m}^{-3}$ was $0.025 \pm 0.011$, a value consistent with the literature (0.021-0.178). While the focus of this study has been examination of the particle-phase measurements, the gas-phase photooxidation products have also been examined.

The contribution of SOA products from 13BD oxidation to ambient $\mathrm{PM}_{2.5}$ was investigated by analyzing a series of ambient $\mathrm{PM}_{2.5}$ samples collected in several locations around the United States. In addition to the occurrence of several organic compounds in field and laboratory samples, glyceric acid, $d$ threitol, erythritol, erythrose, and threonic acid were found to originate only from the oxidation of 13BD based on our previous experiments involving chamber oxidation of a series of hydrocarbons. Initial attempts have been made to quantify the concentrations of these compounds. The average concentrations of these compounds in ambient $\mathrm{PM}_{2.5}$ samples from the California Research at the Nexus of Air Quality and Climate Change (CalNex) study ranged from 0 to approximately $14.1 \mathrm{ng} \mathrm{m}^{-3}$. The occurrence of several other compounds in both laboratory and field samples suggests that SOA originating from 13BD oxidation could contribute to the ambient aerosol mainly in areas with high 13BD emission rates.

\section{Introduction}

Atmospheric organic carbon (OC) from anthropogenic sources forms a large portion of urban ambient organic aerosol. During the last century, the source of anthropogenic hydrocarbons increased significantly due to growth in population and energy demand. The sources of these hydrocar- 
bons are as varied as the species that make up the organic aerosol, and their oxidation is known to lead to the formation of organic aerosol. In the last two decades, considerable effort has been devoted to understanding secondary organic aerosol (SOA) and ground-level ozone formation from biogenic and anthropogenic hydrocarbons (Kanakidou et al., 2005; Hallquist et al., 2009). SOA often constitutes a significant fraction of particles less than $2.5 \mu \mathrm{m}$ in diameter $\left(\mathrm{PM}_{2.5}\right)$, and can have significant impacts on the physical and chemical characteristics of ambient aerosol affecting climate and air quality from global to regional and local scales. Numerous studies have shown that several atmospheric processes, including visibility reduction (Sisler and Malm, 1994) and changes in direct radiative forcing that might affect the global climate (Charlson et al., 1992), are affected by ambient $\mathrm{PM}_{2.5}$. Exposure to $\mathrm{PM}_{2.5}$ has been implicated in increases in human mortality and morbidity levels, and decreased PM levels have been shown to be associated with increased life expectancy (Pope et al., 2009). To date, the chemical composition of ambient aerosol particles, in particular the organic fraction originating from anthropogenic sources, has not been fully characterized. As the understanding of the chemical composition and toxicology associated with these particles develops, more accurate compositional data might be required.

In the past, hydrocarbons possessing five or fewer carbon atoms were generally not considered significant contributors to SOA formation (Grosjean and Seinfeld, 1989). Recently, however, a series of biogenic and anthropogenic conjugated dienes with five or fewer carbon atoms (e.g., isoprene, 1,3butadiene [13BD], 2-methyl-3-butene-2-ol) have been shown to contribute to SOA formation (Claeys et al., 2004; Edney et al., 2005; Kroll et al., 2006; Surratt et al., 2006, 2010; Sato et al., 2011; Jaoui et al., 2012; Zhang et al., 2012, 2014; Angove et al., 2006). Although significant advances have been made toward elucidating 13BD oxidation products and their role in SOA formation, the importance of 13BD to atmospheric SOA formation is not well known at present, but its contribution could be significant in urban areas influenced by high 13BD emissions.

1,3-Butadiene, a conjugated diene, is considered a significant anthropogenic organic compound, with an annual emission rate of 6 million tons worldwide (Berndt and Böge, 2007), and can serve as a functional analog for isoprene. 13BD is widely used in the chemical industry, mainly through processing of petroleum to make synthetic rubber, resins, and plastics (Berndt and Böge, 2007). 13BD is classified as a hazardous compound in the 1990 Clean Air Act Amendments (CAAA; US EPA, 1996), a carcinogenic and toxic pollutant, and a genotoxic chemical in humans and other mammals (Acquavella, 1996; US EPA, 2002). The main sources of 13BD in the atmosphere include automobile exhaust as a combustion byproduct, tobacco smoke, gasoline evaporative emissions, biomass burning, and forest fires (Anttinen-Klemetti et al., 2006; Dollard et al., 2001; Eatough et al., 1990; Pankow et al., 2004; Penn and Snyder, 1996; Ye et al., 1998; Thornton-Manning et al., 1997; Sorsa et al., 1996; Hurst, 2007). The mixing ratio of 13BD at the low ppb level was measured in the ambient atmosphere (US EPA, 2002; Dollard et al., 2001; Vimal et al., 2008; Duffy and Nelson, 1997), while higher concentrations up to $15 \mathrm{ppb}$ have been observed in areas close to plastic and rubber facilities, inside moving vehicles, and in road traffic tunnels. Due to the relatively high volatility of $13 \mathrm{BD}$, its main removal from the atmosphere is through reactions with $\mathrm{OH}, \mathrm{O}_{3}, \mathrm{NO}_{3}$, and $\mathrm{Cl}$ to produce a number of potentially toxic products (e.g., acrolein, formaldehyde), which are also considered air toxics under the CAAA (Liu et al., 1999; Notario et al., 1997; Kramp and Paulson, 2000; Doyle et al., 2004; Angove et al., 2006).

The gas-phase oxidation of 13BD has been investigated in a series of laboratory studies. Most work to date has involved the use of flow tubes and smog chambers to study gas-phase kinetics of 13BD, but in only a few cases have aerosol products been examined. Liu et al. (1999) examined the gas-phase products from the reaction of 13BD with $\mathrm{OH}$ radicals and ozone $\left(\mathrm{O}_{3}\right)$. The major carbonyl products reported were formaldehyde, acrolein, glycolaldehyde, glyceraldehyde, 3-hydroxy-propanaldehyde, hydroxyacetone, and malonaldehyde. Additional non-carbonyl products included furan, 1,3-butadiene monoxide, and 1,3butadiene diepoxide. Berndt and Böge (2007) reported yields of formaldehyde $(0.64 \pm 0.08)$, acrolein $(0.98 \pm 0.12)$, 4hydroxy-2-butanal $(0.23 \pm 0.10)$, nitrates $(0.06 \pm 0.02)$, and furan $(0.046 \pm 0.014)$ from the $\mathrm{OH}$ radical reactions with 13BD conducted in a flow reactor. Kramp and Paulson (2000) studied the formation of two toxic gas reaction products, acrolein and 1,2-epoxy-3-butene from the ozonolysis of 13BD, and reported yields of $52 \pm 7 \%$ for acrolein and $3.1 \pm 0.5 \%$ for 1,2-epoxy-3-butene. Sato (2008) reported the presence of nitric acid, glyoxylic acid, pyruvic acid, oxalic acid, tetrols, nitrooxybutanetriols, and dinitrooxybutanediols in an experiment involving the photooxidation of a $13 \mathrm{BD} / \mathrm{NO} / \mathrm{CH}_{3} \mathrm{ONO} /$ air mixture in which an $\mathrm{SOA}$ yield of 0.025 was found. Recently, Sato et al. (2011) studied SOA formation from $13 \mathrm{BD} / \mathrm{NO}_{\mathrm{x}}$ and $13 \mathrm{BD} / \mathrm{NO}_{\mathrm{x}} / \mathrm{H}_{2} \mathrm{O}_{2}$ reactions, and found SOA yields between 0.021 and 0.178 . In that study, a series of oligomeric compounds were tentatively identified, including glyceric acid oligomers and oligoesters formed from the dehydration reaction of nitrooxypolyols and glyceric acid. To date, there have been very limited studies on SOA characterization, and only a few reaction products have been reported (Sato et al., 2011).

The detection of glyceric acid, glycerol, threitol, and erythritol in forest and tropical ambient samples (Decesari et al., 2006; Wang et al., 2008; Claeys et al., 2010; $\mathrm{Fu}$ et al., 2010), in which erythritol was considered a marker for fungal spores or biomass burning (Claeys et al., 2010; Fu et al., 2010), clearly suggests the importance of $13 \mathrm{BD}$ chemistry in the atmosphere. Laboratory experi- 
ments have shown that glyceric acid, which has a skeleton with four carbon atoms similar to that of 13BD, represents a building block of oligomers and oligoesters in 13BD SOA (Sato et al., 2011). High emissions of 13BD in urban areas could be a significant source of $\mathrm{C} 4$ polyols, ozone, acrolein, and formaldehyde, and could influence the urban atmospheric chemistry. $\mathrm{C} 4$ polyols, which are known to have high water solubility, were not found to contribute to cloud formation any more than other atmospheric organic compounds (Ekström et al., 2009).

Given the presence of threitol, erythritol, and glyceric acid in forest areas and the high emission of 13BD (a possible precursor to these compounds) in rural areas, it is crucial to assess the extent to which we understand SOA formation from the oxidation of $13 \mathrm{BD}$. In this paper, gas and particle organic compounds from the photooxidation of 13BD in the presence and absence of $\mathrm{NO}_{\mathrm{x}}$ were examined. Reaction products in the gas phase were measured using derivatization and nonderivatization techniques. Organic compounds in the particle phase were examined as well as aerosol yields and other aerosol properties. The main focus was to identify organic compounds that can be used as possible unique markers in ambient aerosol. Based on the analysis of field and laboratory samples, the tracer method reported by Kleindienst et al. (2007) was then used to estimate the contribution of 13BD to organic aerosol in ambient air.

\section{Materials and methods}

All chemicals, including the derivatization reagents $O$-(2,3,4,5,6-pentafluorobenzyl)hydroxylamine hydrochloride (PFBHA) and a combination of $N, O$-bis (trimethylsilyl) trifluoroacetamide (BSTFA) with $1 \%$ of trimethylchlorosilane (TMCS) as catalyst, were purchased from Aldrich Chemical Co. (Milwaukee, WI) at the highest purity available and were used without further purification.

Experiments were conducted in a $14.5 \mathrm{~m}^{3}$ parallel-piped, stainless-steel, fixed-volume chamber with $40 \mu \mathrm{m}$ TFE Teflon coated walls. A combination of fluorescent bulbs was used in the chamber to provide radiation distributed over the actinic portion of the spectrum, similar to solar radiation between 300 and $400 \mathrm{~nm}$. UV-313 sunlamps were also used for some irradiations in the absence of $\mathrm{NO}_{\mathrm{x}}$. The smog chamber was operated either in static mode (as a conventional batch reactor) or, for experiments requiring large sampling volumes, in dynamic mode (flow mode), to produce a steady-state concentration of gas- and particle-phase reaction products. The relative humidity and temperature were measured using an Omega Engineering, Inc. (Stamford, CT) digital thermo-hygrometer (model RH411). An integrating radiometer (Eppley Laboratory, Inc., Newport, RI) was used to monitor light intensity continuously. Details of the chamber and its operation can be found in Kleindienst et al. (2006).
Experiments were conducted in either the absence or presence of $\mathrm{NO}_{\mathrm{x}}$. The influence of aerosol acidity as well as relative humidity on SOA formation is described in an accompanying paper (Lewandowski et al., 2014). For experiments with $\mathrm{NO}_{\mathrm{x}}, 13 \mathrm{BD}$ and $\mathrm{NO}$ were added to the chamber through flow controllers to the target concentration. For experiments in the absence of $\mathrm{NO}_{x}$, the photolysis of $\mathrm{H}_{2} \mathrm{O}_{2}$ was the source of $\mathrm{OH} . \mathrm{H}_{2} \mathrm{O}_{2}$ as a $50 \%$ aqueous solution was injected through a syringe pump into a heated glass bulb where it vaporized and then was mixed rapidly by the main dilution air flow. $\mathrm{H}_{2} \mathrm{O}_{2}$ concentrations were determined by UV absorption using a conventional ozone monitor, as described previously (Kleindienst et al., 2009). For these experiments, 13BD was added as described above. Ammonium sulfate seed aerosol was also introduced into the chamber for all experiments to serve as a condensing medium for semivolatile organic products that might form.

$\mathrm{NO}$ and $\mathrm{NO}_{\mathrm{x}}$ were monitored with a TECO (Franklin, MA) oxides of nitrogen analyzer (model 42C) with an inline nylon filter used to prevent nitric acid from entering the analyzer. Ozone was measured with a Bendix (Lewisburg, WV) ozone monitor (model 8002). 13BD concentrations were measured in the inlet and within the chamber in a semi-continuous fashion by gas chromatography with flame ionization detection (GC-FID).

Low molecular weight carbonyl and dicarbonyl compounds including formaldehyde, glyoxal, and acrolein were identified and quantified using derivatization with DNPH (2,4-dinitrophenyl-hydrazine). Air samples were drawn for $20 \mathrm{~min}$ at a rate of $0.50 \mathrm{~L} \mathrm{~min}^{-1}$ through an impinger containing $5 \mathrm{~mL}$ of a DNPH solution in acetonitrile. The resulting solutions were analyzed by high-performance liquid chromatography with a ultraviolet detector (HPLC/UV) (Smith et al., 1989). An external standard solution containing 16 hydrazones and dihydrazones was used for the identification and quantification of compounds formed during the reaction. For carbonyl compounds whose standards are not available, the technique allows their concentrations to be estimated from the average molar extinction coefficient of the standard compounds. Since the extinction coefficient is largely dependent on the chromophore and not on the substituent group (Smith et al., 1989), these hydrazones show a high degree of consistency. Peroxyacryloyl nitrate (APAN) was also measured in this study.

Gas-phase compounds with higher molecular weights were collected with $60 \mathrm{~cm}$, four-channel XAD4-coated annular denuders. The denuders were analyzed for organic compounds by extracting them in a $1: 1$ dichloromethane/methanol mixture and then derivatizing with a BSTFA/TMCS mixture (Jaoui et al., 2004). Ketopinic acid (KPA) was used as an internal standard. Extracts were then analyzed by gas chromatography-mass spectrometry (GC-MS) using the techniques described below. 
Organic carbon concentrations in the particles were measured using a semi-continuous elemental carbon-organic carbon (EC-OC) instrument (Sunset Laboratories, Tigard, OR). The EC-OC instrument uses a quartz filter housed within the oven for the analysis. SOA from the chamber was pumped at a rate of $8 \mathrm{~L} \mathrm{~min}^{-1}$ through the quartz filter. To remove the interference of gas-phase organic compounds in the effluent, a carbon-strip denuder was placed in line before the quartz filter. The duty cycle for the OC measurement was $0.75 \mathrm{~h}$, with a sample collection time of $0.5 \mathrm{~h}$ and an analysis time of $0.25 \mathrm{~h}$.

SMPS (Scanning Mobility Particle Sizer) (model 3071A, TSI, Inc., Shoreview, MN) and CPC (Condensation Particle Counter) (model 3010, TSI, Inc., Shoreview, MN) instruments were used to measure the aerosol size distribution, volume, and total number density. The SMPS operating conditions were $2 \mathrm{~L} \mathrm{~min}^{-1}$ sheath flow, $0.2 \mathrm{~L} \mathrm{~min}^{-1}$ sample flow, and 19 to $982 \mathrm{~nm}$ size scan. The effective enthalpies of vaporization of 13BD aerosol were also measured with the SMPS by adding a heated inlet, which allows the aerosol to be subjected to a range of fixed temperatures (Offenberg et al., 2006).

Aerosol samples were collected at a flow rate of $15 \mathrm{~L} \mathrm{~min}^{-1}$ with $47 \mathrm{~mm}$ glass-fiber filters (Pall Gelman Laboratory, Ann Arbor, MI) for offline analysis. These samples were sonicated with methanol, and the extracts were derivatized with a BSTFA/TMCS mixture (Jaoui et al., 2004). The resulting derivatized extracts were analyzed by GCMS on a ThermoQuest (Austin, TX) GC coupled with an ion trap mass spectrometer. The temperature of the injector was $270^{\circ} \mathrm{C}$, and the $\mathrm{GC}$ was operated in splitless mode. A $60 \mathrm{~m}, 0.25 \mathrm{~mm}$ inner diameter, RTx-5MS column (Restek, Inc., Bellefonte, PA) with a $0.25 \mu \mathrm{m}$ film thickness was used. The oven initial temperature was $84^{\circ} \mathrm{C}$ for $1 \mathrm{~min}$, which was then increased by a temperature ramp of $8^{\circ} \mathrm{C} \mathrm{min}^{-1}$ to $200^{\circ} \mathrm{C}$, followed by a $2 \mathrm{~min}$ hold, and then a second ramp of $10^{\circ} \mathrm{C} \mathrm{min}^{-1}$ to $300^{\circ} \mathrm{C}$. The ion source, ion trap, and interface temperatures were 200,200 , and $300^{\circ} \mathrm{C}$, respectively. $2 \mu \mathrm{L}$ of the extract was injected in $\mathrm{CI}$ and/or EI modes.

For the batch mode experiments, $\mathrm{NO}_{\mathrm{x}}$ and 13BD were introduced continuously into the chamber at the beginning of the experiment until steady state was reached. Then, the reaction was started by turning off the reactant $\left(\mathrm{NO}_{\mathrm{x}}\right.$ and 13BD) flows at the same time the lights were turned on. Samples were taken for gas and particle constituents at sampling periods appropriate for the required masses needed for analysis. In flow mode experiments, reactants were added to the chamber continuously, and the effluent was withdrawn at the same flow rate for filter collection and online gas and particle analysis. The chamber was operated as a batch reactor in experiments ER439 and ER442 and as a flow reactor with a nominal total flow of $60 \mathrm{~L} \mathrm{~min}^{-1}$ to produce the steady-state reaction mixtures in ER440, ER441, ER443, and ER444 (Table 1). Irradiation ER439 was conducted as a survey experiment only, and was used in GC-MS analy- sis to identify compounds. Experiment ER442, in which six sample denuders and filters were collected simultaneously, was carried out to investigate time profiles of reaction products using a BSTFA/TMCS mixture derivatization. The dynamic experiments were also conducted in stages by irradiating $13 \mathrm{BD} / \mathrm{NO}_{\mathrm{x}}$ or $13 \mathrm{BD} / \mathrm{H}_{2} \mathrm{O}_{2}$ mixtures in the absence or presence of $\mathrm{SO}_{2}$ or acidic seed to produce acidic sulfate aerosol. For these experiments, the reactant mixture at each stage was allowed to come to steady state over a period of 18 to $24 \mathrm{~h}$ before sampling began. The results of these experiments are reported in an accompanying paper (Lewandowski et al., 2014).

In addition to laboratory experiments, ambient $\mathrm{PM}_{2.5}$ samples were collected on either quartz or Teflon-impregnated glass-fiber filters. Field sample filters were Soxhlet extracted, and the resulting extracts were evaporated to dryness and derivatized with a BSTFA/TMCS mixture (Jaoui et al., 2004). Detailed descriptions of some of these field campaigns have been provided by Lewandowski et al. (2007, 2008) and Kleindienst et al. (2010). The focus of the field sample analysis has been to investigate the presence of 13BD organic tracer compounds in ambient $\mathrm{PM}_{2.5}$.

\section{Results and discussion}

The initial conditions for experiments involving the oxidation of 13BD are given in Table 1. For experiments conducted in the presence of $\mathrm{NO}_{\mathrm{x}}$, the initial 13BD concentrations ranged from 3.2 to $8.4 \mathrm{ppmC}$, and the $\mathrm{NO}$ concentrations ranged from 340 to $917 \mathrm{ppb}$. Most experiments were conducted under dry conditions ( $\mathrm{RH}<3 \%$ ), except for ER444-1 (Table 1). In the absence of $\mathrm{NO}_{\mathrm{x}}$, the initial $\mathrm{H}_{2} \mathrm{O}_{2}$ concentration was 2.2 ppm for ER441-1 and 3.8 ppm for ER443-1.

ER439 was conducted as a survey experiment in which sufficient aerosol mass was collected on glass-fiber (GF) filters and used for GC-MS analysis solely for the purpose of identifying reaction products. The gas-phase and aerosol extracts were solvent extracted, derivatized, and analyzed by GC-MS or HPLC. Gas and aerosol extracts were derivatized using BSTFA or PFBHA + BSTFA double derivatization. These techniques provide a sensitive method for identifying and quantifying low concentrations of lightly to highly oxidized organic compounds. The BSTFA single derivatization technique provides good quantitative analysis due to both its simplicity and its efficiency (Jaoui et al., 2004). Although the double derivatizations are not quantitatively rigorous, they provide additional structural information that aids in identification of organic constituents by derivatizing the carbonyls that otherwise would not be detected by BSTFA derivatization alone.

The analysis of laboratory-generated gas-phase and SOA products from 13BD oxidation shows a series of organic compounds containing ketone, carboxylic acid, and/or alcoholic functions. Many of these compounds do not have au- 
Table 1. Initial conditions for experiments involving 1,3-butadiene (13BD) oxidation. The experiments were conducted with the chamber operated in a dynamic (flow) mode, except for ER439 and ER442 conducted in static (batch) mode. T: temperature; RH: relative humidity. Seed aerosol at $10 \mu \mathrm{g} \mathrm{m}^{-3}$ was used. GC-MS analysis was done only when $\mathrm{NO}_{\mathrm{x}}$ was present in the system.

\begin{tabular}{llrrrrrr}
\hline Exp. no. & Purpose & $\begin{array}{r}\text { 13BD } \\
(\mathrm{ppm} \mathrm{C})\end{array}$ & $\begin{array}{r}13 \mathrm{BD} \\
\left(\mu \mathrm{g} \mathrm{m}^{-3}\right)\end{array}$ & $\begin{array}{r}\mathrm{NO} \\
(\mathrm{ppb})\end{array}$ & $\begin{array}{r}\mathrm{H}_{2} \mathrm{O}_{2} \\
(\mathrm{ppm})\end{array}$ & $\begin{array}{r}T \\
\left({ }^{\circ} \mathrm{C}\right)\end{array}$ & $\begin{array}{r}\mathrm{RH} \\
(\%)\end{array}$ \\
\hline ER439 & $\begin{array}{l}\text { Test, compound } \\
\text { identification }\end{array}$ & 8.4 & 4614 & 553 & - & - & $<3$ \\
ER440-1 & Tracers, parameters & 6.3 & 3454 & 917 & - & 22 & $<3$ \\
ER440-2 & Tracers, parameters & 3.2 & 1736 & 917 & - & 22 & $<3$ \\
ER441-1 & Tracers & 5.4 & 2973 & - & 2.2 & 24 & $<3$ \\
ER442 & Time series, tracers & 5.8 & 3186 & 724 & - & - & $<3$ \\
ER443-1 & Tracers & 6.3 & 3487 & - & 3.8 & 24 & $<3$ \\
ER444-1 & Tracers, parameters & 6.7 & 3656 & 340 & - & 22 & 30 \\
\hline
\end{tabular}

thentic standards, and their identifications were based on the interpretation of the mass spectra of the derivatized compound (Jaoui et al., 2004, 2005). The identification should be regarded as tentative, except for compounds that have authentic standards. The recognition of characteristic ions associated with a particular derivatization scheme was used to guide the analysis of chemical ionization (CI) mass spectra of the derivatives. BSTFA reacts with $-\mathrm{COOH}$ and $-\mathrm{OH}$ groups to form BSTFA derivatives. Characteristic ions are $m / z 73,75,147$, and 149. Adduct ions from the derivatives include $m / z \mathbf{M}^{+\bullet}+73, \mathbf{M}^{+\bullet}+41, \mathbf{M}^{+\bullet}+29$, and $\mathbf{M}^{+\bullet}+1$; fragment ions include $m / z \mathbf{M}^{+\bullet}-15, \mathbf{M}^{+\bullet}-73, \mathbf{M}^{+\bullet}-89$, $\mathrm{M}^{+\bullet}-117, \mathrm{M}^{+\bullet}-105, \mathrm{M}^{+\bullet}-133$, and/or $\mathrm{M}^{+\bullet}-207$. PFBHA reacts with each nonacidic $>\mathrm{C}=\mathrm{O}$ group to form an oxime derivative. In $\mathrm{CI}$ mode, the base peak for most oximes is $\mathrm{M}^{+\bullet}+1$ or 181 , while other fragments/adducts include $m / z \mathbf{M}^{+\bullet}+29, \mathbf{M}^{+\bullet}+41, \mathbf{M}^{+\bullet}-181$, and $\mathbf{M}^{+\bullet}-197$. Double derivatizations result in adducts and fragments that include characteristic ions from each single derivatization. In many cases, samples were run in electron ionization (EI) mode to produce greater fragmentation for additional structural information.

\subsection{Product identification}

In the present study, mass spectra of more than 60 derivative compounds have been recorded, for which representative examples are shown. The approach used for their identification is as follows: peaks detected in blank and background chamber samples were eliminated first. A peak was associated with a reaction product only if its corresponding mass spectrum was consistent with the fragmentation pattern of the derivatization reagent used as noted above. All recorded spectra were compared with spectra derived from various reference compounds and the literature. Typical total ion chromatograms of samples taken from experiment ER439 (Table 1) are shown in Fig. 1 as BSTFA (top) and PFBHA + BSTFA (bottom) derivatives of 13BD SOA. For clarity, only the main products are shown. GC-MS analysis of the mixture showed the presence of 10 significant peaks in the BSTFA derivatives and 7 significant peaks in the PFBHA + BSTFA derivatives. However, a significant number of relatively small peaks associated with both derivatizations were clearly observed in the particle phase, reflecting the complexity of the oxidation of 13BD. Compounds identified in the present study are summarized in Table 2 , which contains proposed structures for products identified when possible as well as molecular weights (MWs) of the underivatized compounds $(\mathrm{Mc})$.

\subsubsection{SOA products}

\section{Aerosol parameters}

The production of aerosol was found to be dependent on the conditions under which the experiments were carried out, in particular the presence of $\mathrm{NO}_{\mathrm{x}}$ in the system. The oxidation of 13BD produced non-negligible levels of aerosol. Except for a minor organic nitrate channel, the photooxidation system in the presence of $\mathrm{NO}_{\mathrm{x}}$ converts virtually all $\mathrm{RO}_{2}$ formed into $\mathrm{RO}$ radicals, which then decompose or isomerize to produce carbonyl or hydroxycarbonyl compounds (Atkinson, 2000). Without $\mathrm{NO}_{\mathrm{x}}$ in the system, $\mathrm{RO}_{2}$ radicals typically react with $\mathrm{HO}_{2}$ or self-react to produce a product molecule with four carbons while adding functional groups to the product. These products are sufficiently nonvolatile to condense into the particle phase.

The secondary organic carbon yield $\left(Y_{\mathrm{SOC}}\right)$ and secondary organic aerosol yield $\left(Y_{\mathrm{SOA}}\right)$ are generally defined using the following relationships: $Y_{\mathrm{SOC}}=\mathrm{SOC} / \Delta \mathrm{HC}_{\mathrm{C}}$ and $Y_{\mathrm{SOA}}=$ $\mathrm{SOA} / \triangle \mathrm{HC}$, where $\mathrm{SOC}$ is the corrected organic carbon concentration, $\triangle \mathrm{HC}$ is the reacted hydrocarbon mass concentration, and $\triangle \mathrm{HC}_{\mathrm{C}}$ is the reacted carbon mass concentration of the hydrocarbon obtained from Table 3 . The SOA concentration was obtained from gravimetric measurement. The volume concentrations from the SMPS $\left(\mathrm{nL} \mathrm{m}^{-3}\right)$ are also reported in Table 3. The SOA density was estimated using both filter masses and SMPS data (Table 4). An average 
Table 2. Summary of gas-phase and SOA products generated from the oxidation of 1,3-butadiene. Oligoesters presented here are only one possible isomer.

\begin{tabular}{lccc}
\hline Nomenclature & Structure & MW $\left(\mathrm{g} \mathrm{mol}^{-1}\right)$ & BSTFA MW $\left(\mathrm{g} \mathrm{mol}^{-1}\right)$ \\
\hline 1,3-Butadiene & $\mathrm{H}_{2} \mathrm{C}$ & 54 & -
\end{tabular}

Gas phase

Formaldehyde

Acetaldehyde

Acrolein

Glyoxal

Glycolaldehyde

Methylglyoxal

Malonaldehyde

Butenedial

3-Hydroxy-propanaldehyde

Hydroxypyruvaldehyde

Glyceraldehyde<smiles>C=O</smiles><smiles>CC=O</smiles><smiles>C=CC=O</smiles><smiles>O=CC=O</smiles><smiles>O=CCO</smiles><smiles>CC(=O)C=O</smiles><smiles>O=CC=C(C=O)C=O</smiles><smiles>O=C/C=C\C=O</smiles><smiles>O=CCCO</smiles><smiles>O=CC(=O)CO</smiles><smiles>O=C[C@H](O)CO</smiles>

60 
Table 2. Continued.

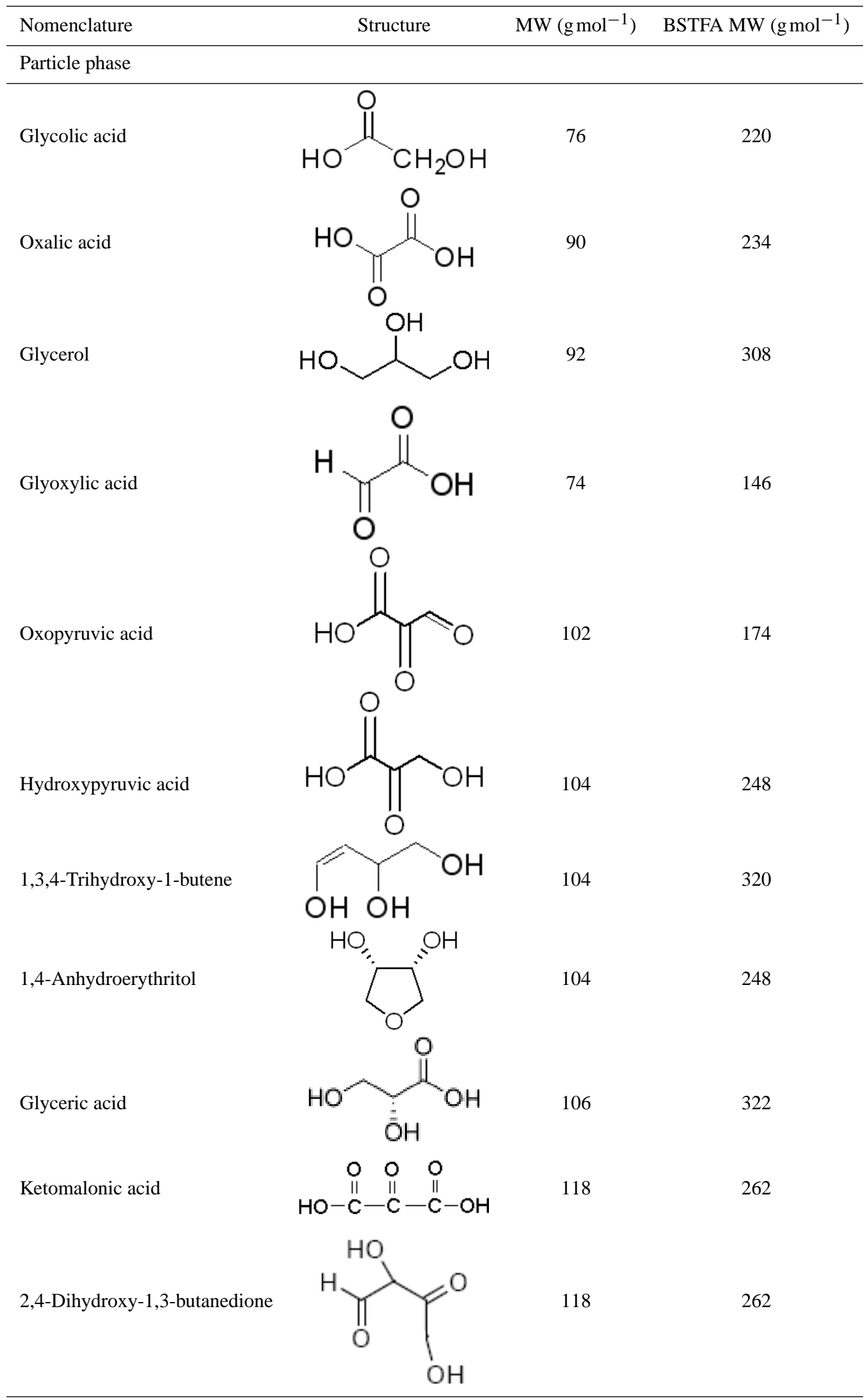


Table 2. Continued.

Nomenclature


Table 2. Continued.

\begin{tabular}{|c|c|c|c|}
\hline Nomenclature & Structure & $\mathrm{MW}\left(\mathrm{g} \mathrm{mol}^{-1}\right)$ & BSTFA MW $\left(\mathrm{g} \mathrm{mol}^{-1}\right)$ \\
\hline \multicolumn{4}{|l|}{ Oligoesters: particle phase } \\
\hline Glyceric acid dimer & & 194 & 482 \\
\hline Glyceric acid-threonic acid ester & & 224 & 584 \\
\hline Glyceric acid-threitol ester & & 210 & 570 \\
\hline Threonic acid-glycerol ester & & 210 & 570 \\
\hline Hydroxypyruvic acid-tetrol ester & & 208 & 496 \\
\hline Glyceric acid-glycerol ester & & 180 & 468 \\
\hline Oxalic acid-glycerol ester & & 164 & 380 \\
\hline Oxalic acid-MW104 & - & 176 & 392 \\
\hline Oxalic acid-glyceric acid & & 178 & 394 \\
\hline Oxalic acid-tetrol & & 190 & 478 \\
\hline Oxalic acid-threonic acid ester & & 208 & 496 \\
\hline Oxalic acid-erythrulose ester & & 192 & 408 \\
\hline Glyceric acid-1,3,4-trihydroxy-1-butene ester & & 192 & 480 \\
\hline Glyceric acid-erythrulose ester & & 224 & 512 \\
\hline Malic acid-glycolic acid ester & & 192 & 408 \\
\hline Malic acid-glycerol & & 208 & 496 \\
\hline Malic acid-hydroxypyruvic acid ester & & 220 & 436 \\
\hline Malic acid-1,3,4-trihydroxy-1-butene ester & & 220 & 508 \\
\hline
\end{tabular}



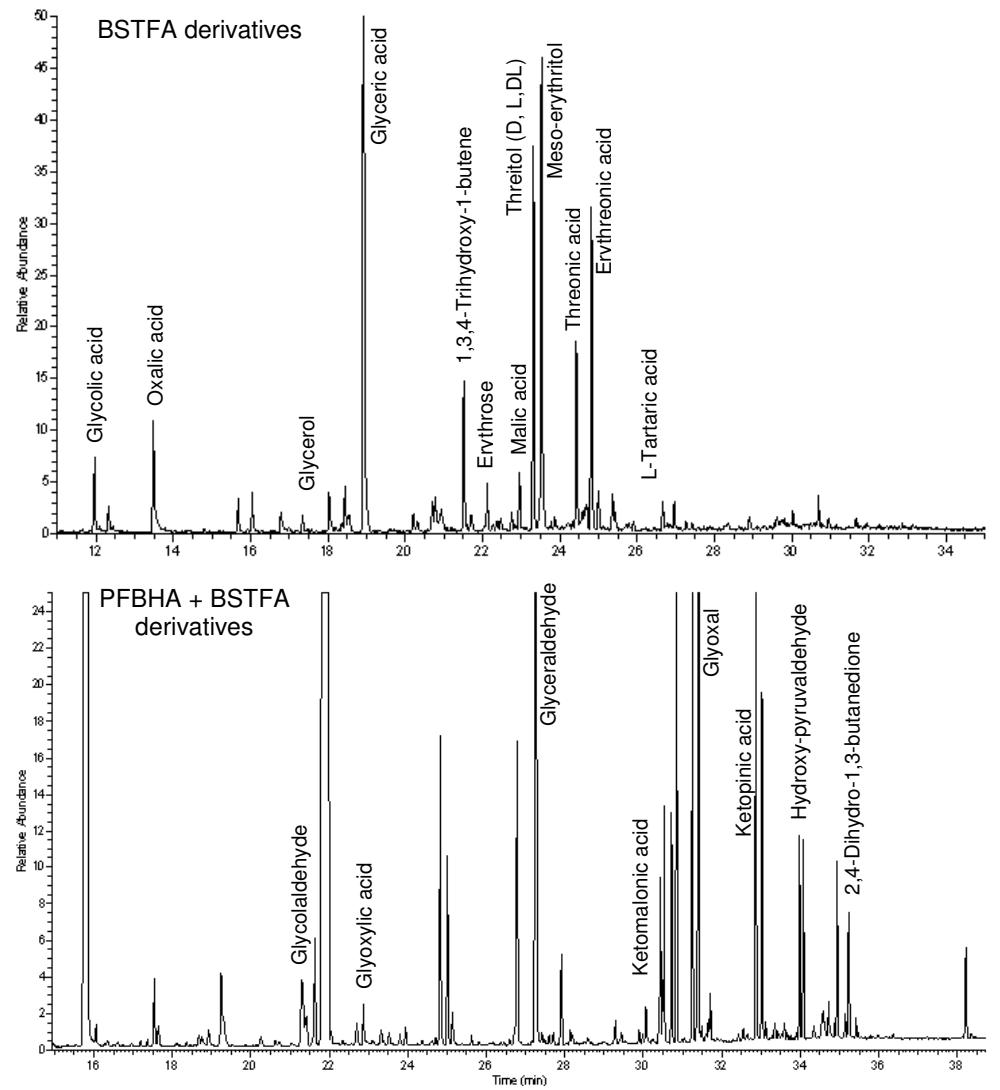

Figure 1. Total ion chromatograms of organic extracts from an irradiated 1,3-butadiene/ $\mathrm{NO}_{\mathrm{x}} /$ air mixture as BSTFA (top) and PFBHA + BSTFA (bottom) derivatives.

density of $1.2 \pm 0.05$ was obtained. Organic carbon and organic aerosol yields and organic mass to organic carbon ratio $(\mathrm{OM} / \mathrm{OC})$ were determined for experiments in which the chamber was operated in a dynamic mode (Table 4). Uncertainties in the yields come from the experimental uncertainties in SOA and the reacted 13BD concentrations. The gravimetric yield values were similar to those measured using the SMPS data. Average SOA and SOC yields of $0.025 \pm 0.011$ and $0.017 \pm 0.013$ were obtained, respectively. SOA yield values were in reasonable agreement with data in the literature (Sato et al., 2011; Sato, 2008). In addition, the effective enthalpy of vaporization $\left(\Delta H_{\text {vap }}^{\text {eff }}\right)$ was measured for the different experiments conducted in this study, and its average value was found to be $-26.08 \pm 1.46 \mathrm{~kJ} \mathrm{~mol}^{-1}$.

\section{Characterization of SOA products}

SOA generated from 13BD oxidation was dominated by oxygenated compounds in which 13BD double bonds were oxidized. Chromatograms from SOA samples either in EI or CI modes indicated the presence of several larger peaks from either BSTFA or PFBHA + BSTFA derivatizations. Figure 2 shows examples of CI mass spectra as BSTFA derivatives for some products detected and identified in the aerosol phase.
A glyceric acid (GA or 2,3-dihydroxypropanoic acid) peak eluted at $18.92 \mathrm{~min}$ was one of the largest peaks detected in the chromatogram in Fig. 1 (top). The GA mass spectrum (Fig. 2, bottom left) shows strong characteristic fragments ion at $\mathrm{m} / \mathrm{z} 323\left[\mathbf{M}^{+\bullet}+1\right], 189\left[\mathbf{M}^{+\bullet}-133\right], 205$ $\left[\mathrm{M}^{+\bullet}-117\right]$, and $307\left[\mathrm{M}^{+\bullet}-15\right]$, and adducts at $\mathbf{M}^{+\bullet}+1$, $\mathrm{M}^{+\bullet}+29$, and $\mathrm{M}^{+\bullet}+41$ that are consistent with the presence of three (-OH) groups, indicating a BSTFA-derivatized molecular weight $(\mathrm{Md})$ of $322 \mathrm{Da}$ (all derivatized and underivatized masses are Dalton (Da), but are not designated as such hereafter).

The BSTFA CI mass spectrum of L-threitol shows characteristic fragment ions at $\mathrm{m} / \mathrm{z} 73,395\left[\mathrm{M}^{+\bullet}-15\right], 321$ $\left[\mathrm{M}^{+\bullet}-89\right]$, and $305\left[\mathrm{M}^{+\bullet}-105\right]$, and an adduct at 411 $\left[\mathrm{M}^{+\bullet}+1\right]$. These fragments and the adduct are consistent with the presence of four $\mathrm{OH}$ groups and an MW of 410 for the derivatized compound and 122 for the underivatized compound. The presence of a peak at $m / z 305\left[\mathbf{M}^{+\bullet}-105\right]$ is consistent with a compound bearing an alcoholic $\mathrm{OH}$ group. This mass spectrum is identical to the one from an L-threitol standard (Fig. 2). The mass spectra of BSTFA derivatives of L- and DL-threitol standards (Fig. 2, top left) are very similar (eluting at the same time), and are only slightly different from the meso-threitol spectrum (Fig. 2, top right); however, they 
Table 3. Reacted 1,3-butadiene and steady-state parameters determined from SOA produced by 1,3-butadiene oxidation.

\begin{tabular}{lrrrrrr}
\hline Experiment no. & $\begin{array}{r}\text { Reacted HC } \\
\left(\mu \mathrm{g} \mathrm{m}^{-3}\right)\end{array}$ & $\begin{array}{r}\text { Reacted } \mathrm{HC} \\
\left(\mu \mathrm{g} \mathrm{Cm}^{-3}\right)\end{array}$ & $\begin{array}{r}\mathrm{O}_{3} \\
(\mathrm{ppb})\end{array}$ & $\begin{array}{r}\mathrm{SOA} \\
\left(\mu \mathrm{g} \mathrm{m}^{-3}\right)\end{array}$ & $\begin{array}{r}\text { SMPS } \\
\left(\mathrm{nL} \mathrm{m}^{-3}\right)\end{array}$ & $\begin{array}{r}\text { SOC } \\
\left(\mu \mathrm{g} \mathrm{C}^{-3}\right)\end{array}$ \\
\hline ER440-1 & 3412 & 3028 & 487 & 140.2 & 117.5 & 49.8 \\
ER440-2 & 1731 & 1536 & 382 & 34.7 & 31.4 & 12.4 \\
ER441-1 & 1558 & 1382 & 48 & 37.7 & 33.5 & 13.6 \\
ER443-1 & 1434 & 1273 & 28 & 22.5 & 18.6 & 8.6 \\
ER444-1 & 2724 & 2417 & 281 & - & - & 17.2 \\
\hline
\end{tabular}

In ER 444-1, a high aerosol seed concentration was used, and SOA parameters were not reported for this experiment.

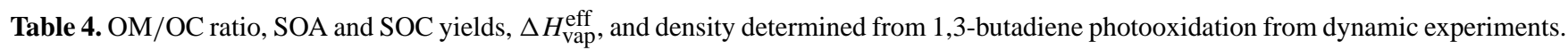

\begin{tabular}{lrrrrr}
\hline Experiment no. & OM/OC & $Y_{\text {SOA }}$ & $Y_{\text {SOC }}$ & $\begin{array}{r}\Delta H_{\text {vap }}^{\text {eff }} \\
\left(\mathrm{kJ} \mathrm{mol}^{-1}\right)\end{array}$ & Density \\
\hline ER440-1 & 2.8 & 0.041 & 0.016 & -27.32 & 1.2 \\
ER440-2 & 2.8 & 0.020 & 0.008 & -27.28 & 1.1 \\
ER441-1 & 2.8 & 0.024 & 0.010 & -25.38 & 1.1 \\
ER443-1 & 2.6 & 0.016 & 0.007 & -24.37 & 1.2 \\
ER444-1 & - & - & 0.007 & - & - \\
Avg. \pm SD & $2.7 \pm 0.09$ & $0.025 \pm 0.011$ & $0.017 \pm 0.013$ & $-26.08 \pm 1.46$ & $1.2 \pm 0.05$ \\
\hline
\end{tabular}

In ER 444-1, a high aerosol seed concentration was used, and SOA parameters were not reported for this experiment.

elute at two different retention times. The peaks associated with these compounds, along with those of threonic acid and erythreonic acid (also called erythronic acid), are among the largest peaks observed in the chromatograms. Note that the mass spectra of the BSTFA derivative of 2-methylglyceric acid, erythrose, and 2,3-dihydroxyisopentanol (Jaoui et al., 2012) are similar, but each compound has its characteristic fragments specific to its structure (i.e., $m / z 247$ for erythrose, $\mathrm{m} / z 293$ for 2-methylglyceric acid, and $m / z 247$ for 2,3dihydroxyisopentanol). They also elute at different retention times. The mass spectrum of threonic acid (Fig. 2) shows strong characteristic fragment ions at $m / z 425\left[\mathbf{M}^{+\bullet}+1\right]$, $189\left[\mathrm{M}^{+\bullet}-133\right], 217\left[\mathrm{M}^{+\bullet}-207\right]$, and $409\left[\mathrm{M}^{+\bullet}-15\right]$, and adducts at $\mathbf{M}^{+\bullet}+1, \mathbf{M}^{+\bullet}+29$, and $\mathbf{M}^{+\bullet}+41$. These fragmentation patterns are very similar to those observed for methyltetrols, so special caution is needed when field samples are analyzed using GC-MS, to avoid designating methyltetrols as threonic acid or erythreonic acid. Note that these compounds elute at different times, and each one contains a few specific fragments (e.g., threonic acid at $m / z 217$, 291, and 307, and methyltetrols at $m / z 319$ and 293).

The BSTFA CI mass spectrum of erythrose shows characteristic fragment ions at $\mathrm{m} / \mathrm{z} 73,321\left[\mathrm{M}^{+\bullet}-15\right], 247$ $\left[\mathrm{M}^{+\bullet}-89\right]$, and $231\left[\mathrm{M}^{+\bullet}-105\right]$, and adducts at $\left[\mathrm{M}^{+\bullet}+1\right]$, $\left[\mathrm{M}^{+\bullet}+29\right]$, and $\left[\mathrm{M}^{+\bullet}+41\right]$. These fragments and adducts are consistent with the presence of three $\mathrm{OH}$ groups and an MW of 336 for the derivatized compound and 120 for the underivatized compound. The absence of a peak at $\mathrm{m} / \mathrm{z}$ $219\left[\mathrm{M}^{+\bullet}-117\right]$ is consistent with the absence of a car- boxylic group. The mass spectrum associated with PFBHA + BSTFA double derivatization shows fragment ions at $\mathrm{m} / \mathrm{z}$ $73,181,442\left[\mathrm{M}^{+\bullet}-89\right]$, and $516\left[\mathrm{M}^{+\bullet}-15\right]$, and adducts at $\left[\mathbf{M}^{+\bullet}+1\right],\left[\mathbf{M}^{+\bullet}+29\right]$, and $\left[\mathbf{M}^{+\bullet}+41\right]$. These fragmentation patterns are consistent with the presence of one $\mathrm{CO}$ group and an MW of 531 for the derivatized compound and 120 for the underivatized compound. The compound associated with these peaks was identified as erythrose (Table 2 and Fig. 2). Other compounds identified in the particle phase in the present study were glyoxal, glycoladehyde, oxalic acid, malic acid, tartaric acid, glyceraldehydes, and erythrulose (see Table 2 for more products). Additional compounds might include high molecular weight organonitrates that could have been present in the SOA or the gas phase, but that were not detected by the analytical techniques used in this study (Sato et al., 2011). In addition, a large number of other smaller peaks were observed to elute late in the chromatogram in the particle phase, reflecting the complexity of the oxidation of 13BD; these were mainly associated with organoesters.

\section{.2 Oligoesters}

Although several monomer compounds (e.g., glyceric acid, threitol, glycerol, erythrose, erythreonic acid, and erythritol) with MWs less than 150 were present in chamber SOA, their formation is consistent with direct oxidation of 13BD in the gas phase. A series of other smaller peaks were present in the chromatograms in which the associated 
L- or DL-threitol standard

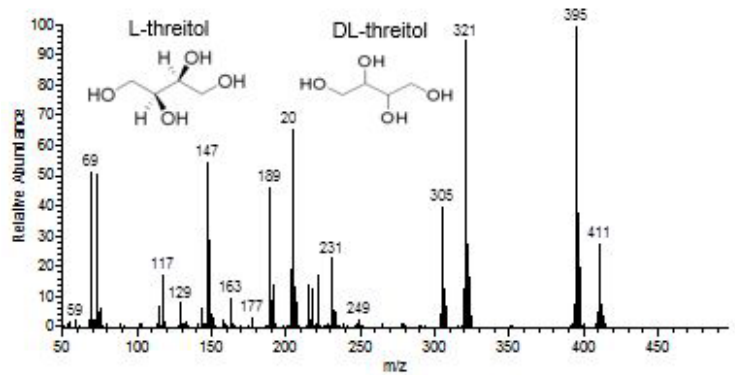

L or DL-threitol in 13BD SOA

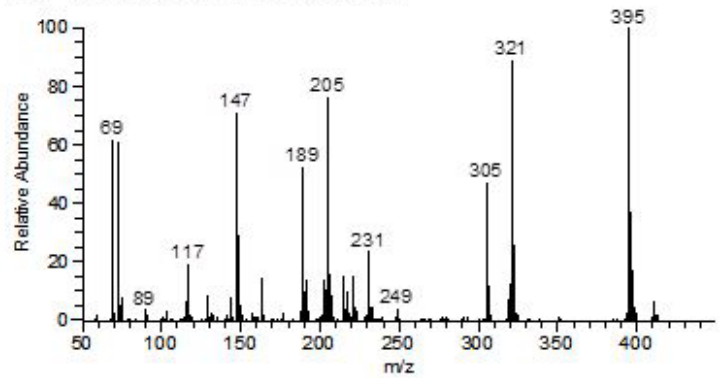

erythrose in 13BD SOA

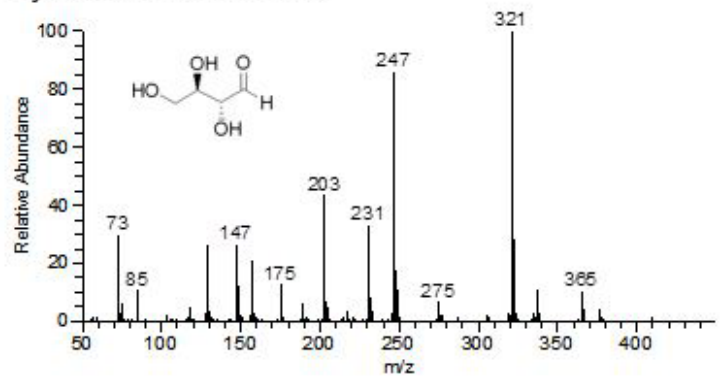

glyceric acid in 13BD SOA

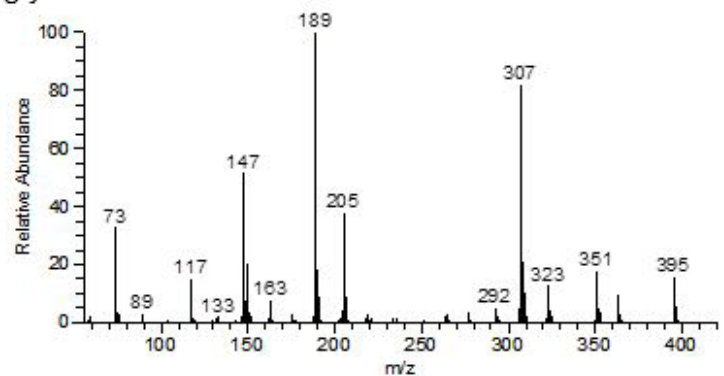

meso-threitol standard

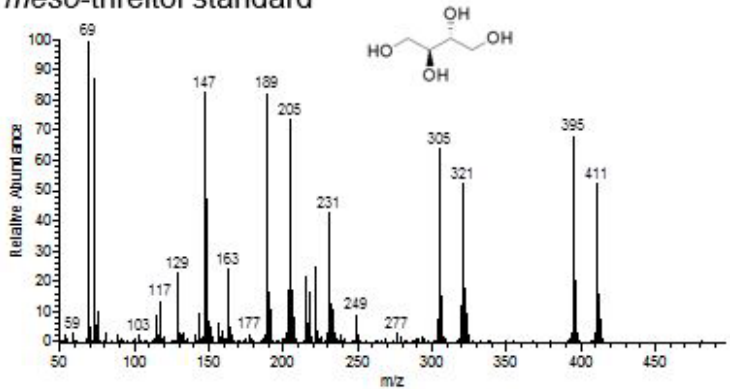

meso-threitol in 13BD SOA

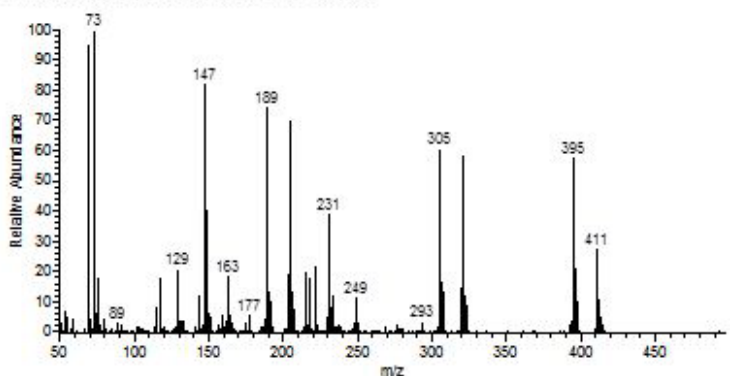

threonic acid in 13BD SOA

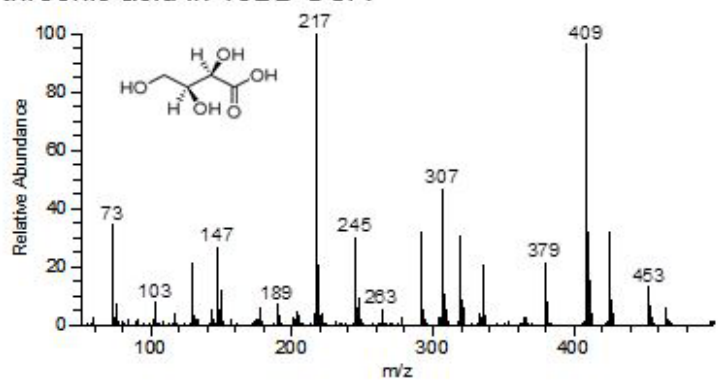

1,4-anhydroerythritol in 13BD SOA

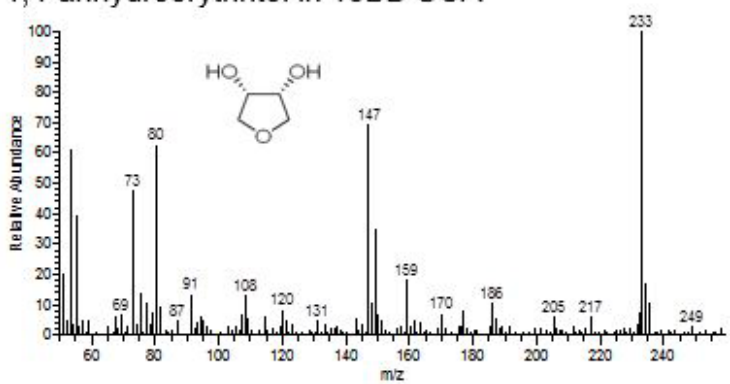

Figure 2. CI mass spectra of some organic compounds present in irradiated 1,3-butadiene/ $\mathrm{NO}_{\mathrm{x}} /$ air.

mass spectra could not be associated with compounds resulting from direct gas-phase oxidation of 13BD. A detailed analysis of their mass spectra indicates that high molecular weights are associated with these peaks, and is consistent with oligomers or oligoesters formed through heterogeneous reactions, probably in the particle phase. Figure 3 shows 15 $\mathrm{CI}$ mass spectra associated with some of these peaks. These mass spectra show characteristic fragment ions at $m / z$ 73, $\left[\mathrm{M}^{+\bullet}-15\right],\left[\mathrm{M}^{+\bullet}-89\right],\left[\mathrm{M}^{+\bullet}-117\right]$, and $\left[\mathrm{M}^{+\bullet}-105\right]$, and adducts at $\left[\mathrm{M}^{+\bullet}+1\right],\left[\mathrm{M}^{+\bullet}+29\right]$, and $\left[\mathrm{M}^{+\bullet}+41\right]$, consis- tent with BSTFA derivatization for compounds bearing $\mathrm{OH}$ groups. Their interpretation, in general, leads to tentative structural identification, since all authentic standards are unavailable.

Figure 3a, for example, shows a mass spectrum with characteristic fragment ions at $\mathrm{m} / \mathrm{z}, 73,467\left[\mathrm{M}^{+\bullet}-15\right]$, $393\left[\mathrm{M}^{+\bullet}-89\right], 365\left[\mathrm{M}^{+\bullet}-117\right]$, and $377\left[\mathrm{M}^{+\bullet}-105\right]$, and adducts at $483\left[\mathrm{M}^{+\bullet}+1\right], 511\left[\mathrm{M}^{+\bullet}+29\right]$, and 523 $\left[\mathrm{M}^{+\bullet}+41\right]$. These fragments and adducts are consistent with the presence of four $\mathrm{OH}$ groups and a MW of 482 for 

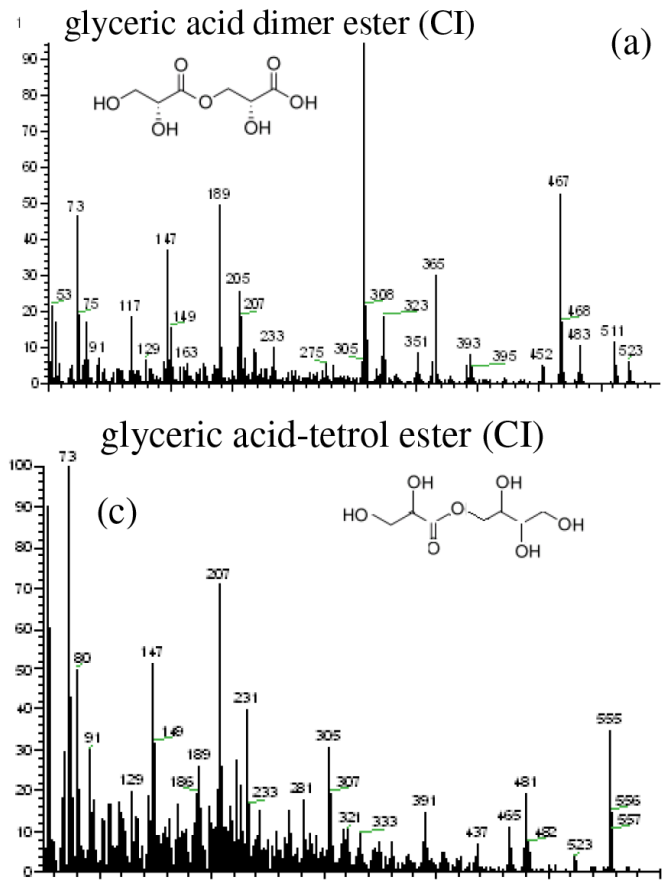

oxalic acid-glycerol ester (CI)

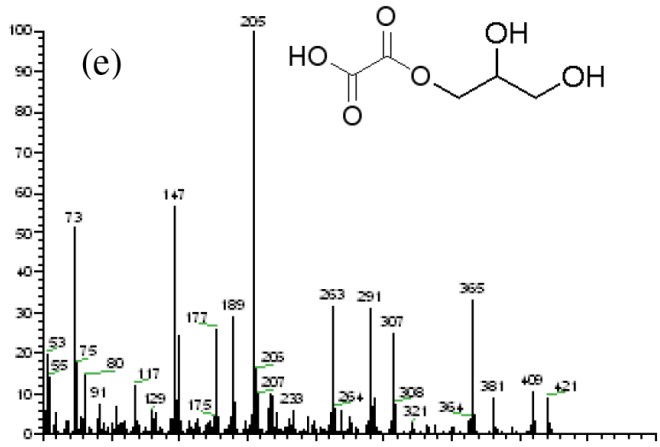

oxalic acid-tetrol ester (CI)

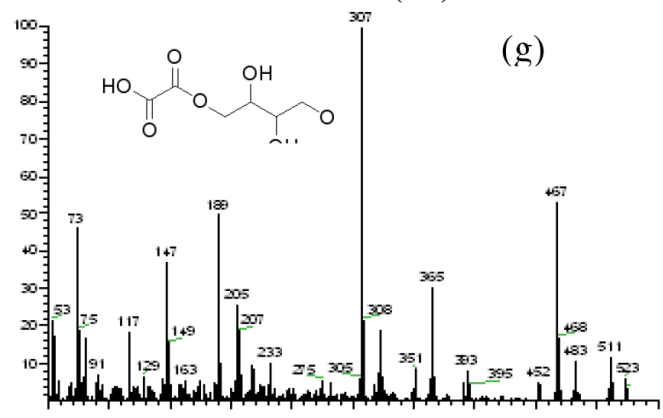

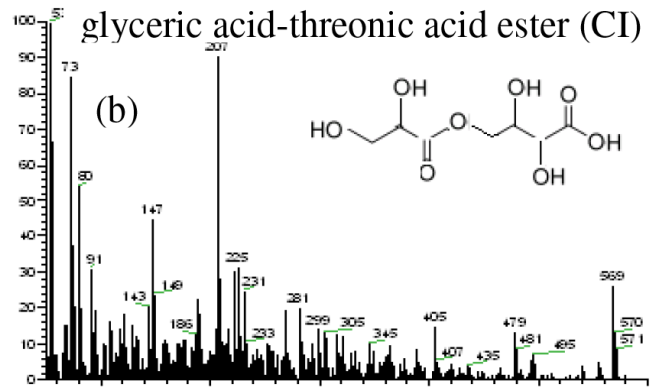

glyceric acid-glycerol ester (CI)

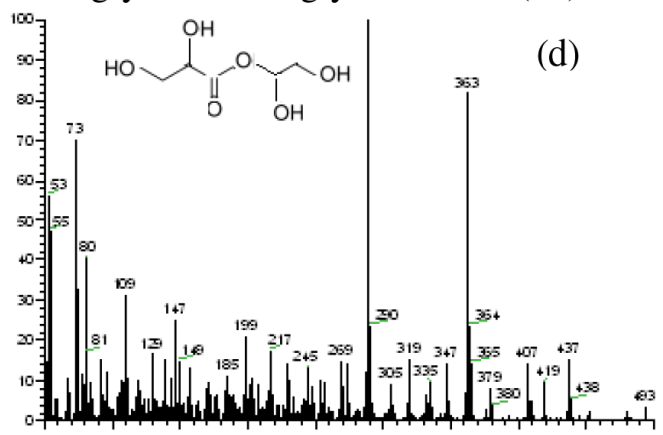

oxalic acid-glyceric acid ester (CI)

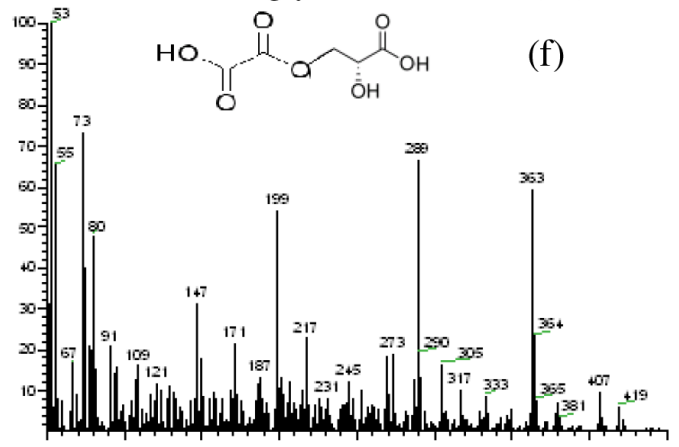

oxalic acid-threonic acid ester $(\mathrm{CI})$

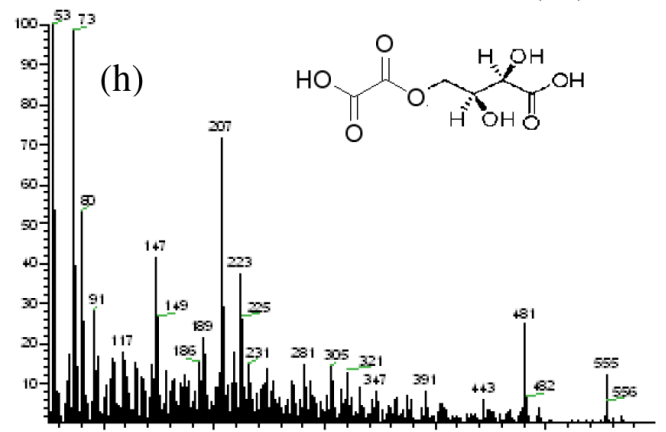

Figure 3.

the derivatized compound and 194 for the underivatized compound. The peaks at $\mathrm{m} / \mathrm{z} 365\left[\mathrm{M}^{+\bullet}-117\right]$ and 377 $\left[\mathrm{M}^{+\bullet}-105\right]$ are consistent with a compound bearing both a carboxylic acid group and an alcoholic $\mathrm{OH}$ group, respectively. The compound associated with this peak was tentatively identified as glyceric acid dimer ester (self-reaction of glyceric acid), preserving two 13BD carbon backbones connected with one oxygen atom.

Figure $3 \mathrm{c}$ shows a mass spectrum with characteristic fragment ions at $\mathrm{m} / \mathrm{z} 73,555\left[\mathrm{M}^{+\bullet}-15\right], 481\left[\mathrm{M}^{+\bullet}-89\right]$, and $465\left[\mathrm{M}^{+\bullet}-105\right]$, and adducts at $571\left[\mathrm{M}^{+\bullet}+1\right]$. These fragments and adducts are consistent with the presence of five 
(i) oxalic acid-erythrulose dimer ester

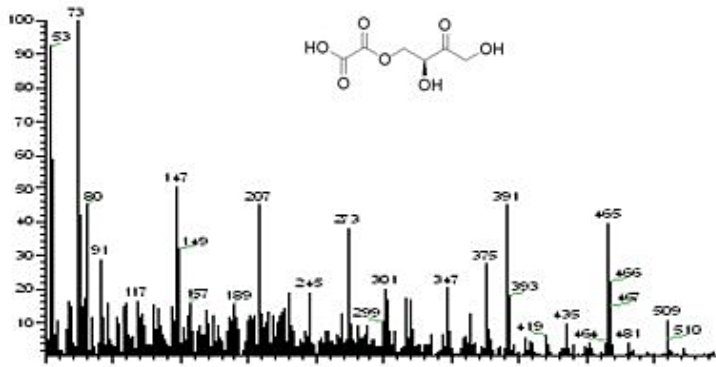

(k) glyceric acid-erythrulose ester

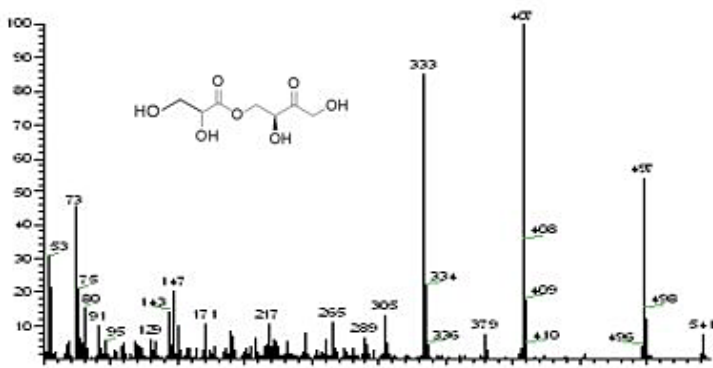

(m) malic acid-glycerol ester

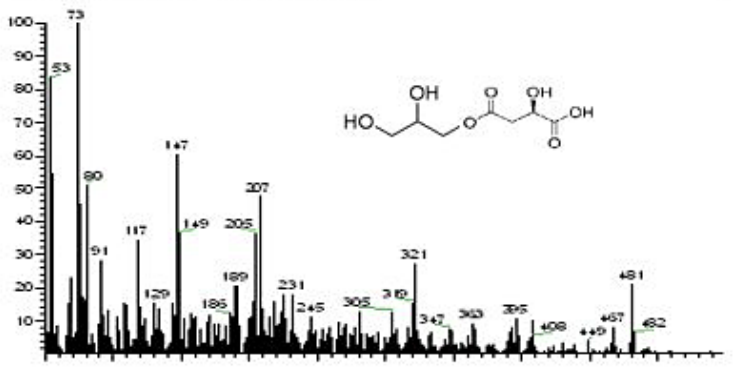

(o) malic acid-1,3,4-trihydroxy-1-buten ester

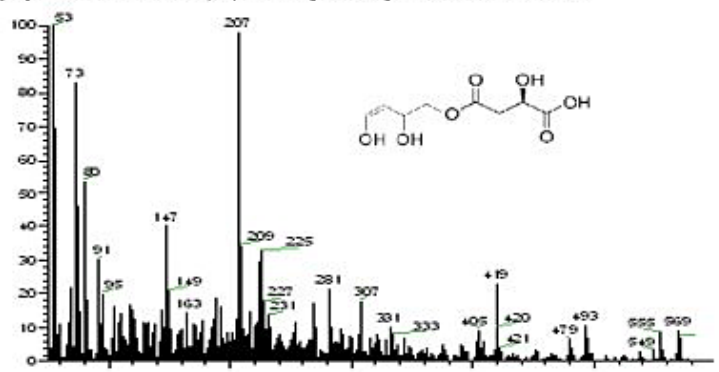

(j) glyceric acid-1,3,4-trihydroxy-1-butene ester

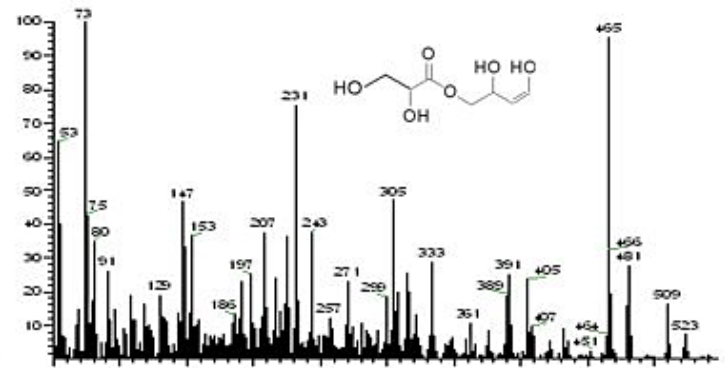

(I) malic acid-glycolic acid ester

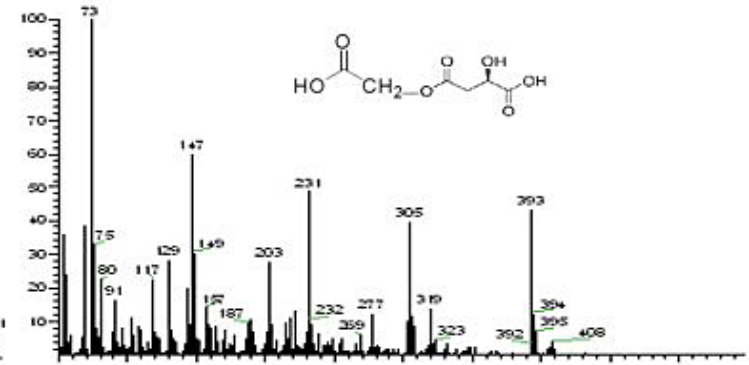

(n) malic acid-hydroxypyruvic acid ester

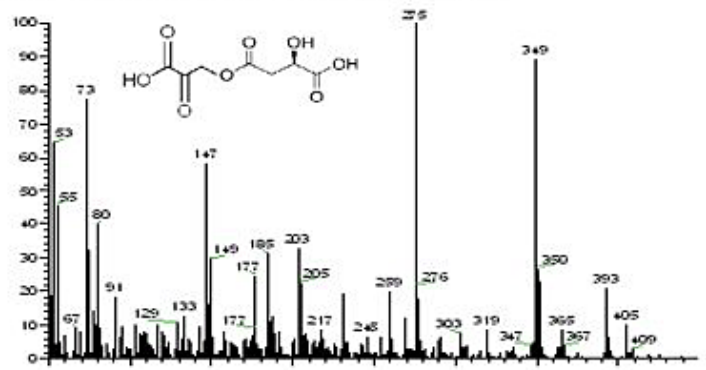

Figure 3. CI mass spectra of oligoester compounds present in irradiated 1,3-butadiene/ $\mathrm{NO}_{\mathrm{x}} /$ air.

$\mathrm{OH}$ groups and an MW of 570 for the derivatized compound and 210 for the underivatized compound. The absence of a peak at $m / z 453\left[\mathrm{M}^{+\bullet}-117\right]$ presents strong evidence of the absence of a carboxylic acid group, and the presence of a peak at $465\left[\mathrm{M}^{+\bullet}-105\right]$ is consistent with the presence of an alcoholic $\mathrm{OH}$ group. The compound associated with this peak was tentatively identified as glyceric acid-tetrol ester. Similar oligoester compounds were tentatively associated with peaks observed in chromatograms from the oxidation of 13BD (Table 2 and Fig. 3). A key element for the identification of high molecular weight species resulting from
13BD oxidation is the presence or absence of peaks at $m / z$ $\left[\mathrm{M}^{+\bullet}-105\right]$ and/or $\left[\mathrm{M}^{+\bullet}-117\right]$. The presence or absence of peaks at $m / z\left[\mathrm{M}^{+\bullet}-105\right]$ and $\left[\mathrm{M}^{+\bullet}-117\right]$ in the BSTFA mass spectrum suggests the presence or absence of alcoholic groups and carboxylic acid, respectively, in the compound associated with the spectrum.

The mass spectra in Fig. 3 show fragmentation patterns consistent with compounds formed through esterification reactions likely occurring in the aerosol phase between an acid and an alcohol, leading to the formation of an ester. This is consistent with results reported by Angove et al. (2006), 

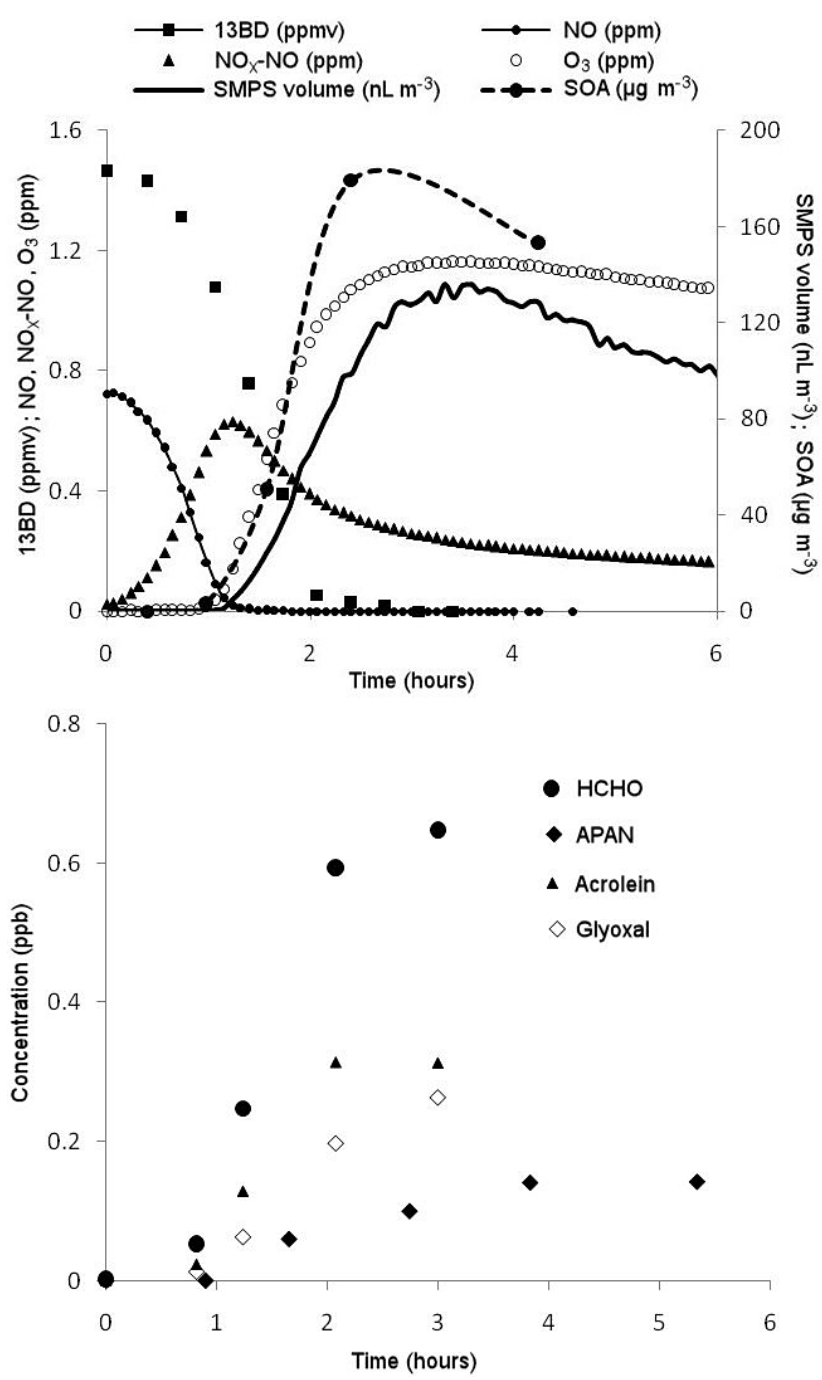

Figure 4. Time profile of gas-phase species from the oxidation of 13BD in experiment ER442. All species were corrected for dilution.

and suggests the presence of $\mathrm{C}=\mathrm{O}$ stretching at 1728, which is indicative of formate esters rather than aldehydes and ketones (Angove et al., 2006). However, recent work by Birdsall et al. (2013) shows that esterification reactions involving organic acid and alcohol under atmospheric conditions are too slow to occur, and cannot account for the oligoesters observed in chamber experiments. Based on this work and prior work (Surratt et al., 2010; Lin et al., 2013), Birdsall et al. (2014) provided evidence that methacrylic acid epoxide (MAE) through hydrolysis reaction plays a key role in isoprene-SOA composition.

\subsection{Time profile of gas-phase and SOA products}

Figure 4 (top) shows the concentrations of $13 \mathrm{BD}, \mathrm{O}_{3}, \mathrm{NO}$, and $\mathrm{NO}_{\mathrm{x}}-\mathrm{NO}$, SMPS volume, and SOA as functions of irradiation time for static experiment ER442. The chamber tem- perature was between 19 and $22^{\circ} \mathrm{C}$ during the entire experiment, and the RH was less than $3 \%$. The wall loss rate constant was $0.064 \mathrm{~h}^{-1}$ for SOA and SMPS. All species were corrected for dilution. SOA and $\mathrm{O}_{3}$ remained very low at the beginning of the experiment, increased slowly as the NO was converted to $\mathrm{NO}_{2}$, and then increased rapidly as the concentration of NO approached zero. The concentration of 13BD started with a rapid decrease that continued steadily for $2 \mathrm{~h}$, after which it began to react slowly and was mostly gone by $3 \mathrm{~h}$. The concentration of NO displayed a trend similar that of $13 \mathrm{BD}$, while $\mathrm{NO}_{2}$ (represented in the figure as $\mathrm{NO}_{\mathrm{x}}-$ $\mathrm{NO}$ ) increased at a rate similar to the decrease in NO, and reached its maximum after $1 \mathrm{~h}$. After $\mathrm{NO}_{2}$ reached and maintained its maximum for approximately $1 \mathrm{~h}$, it started to decrease slowly, reaching approximately $180 \mathrm{ppb}$ at the end of the reaction $(6 \mathrm{~h}) . \mathrm{NO}_{\mathrm{x}}-\mathrm{NO}$ at the end of the reaction was $176 \mathrm{ppb}$, reflecting the presence of nitrated compounds, probably resulting from reaction of $\mathrm{NO}_{2}$ with organic compounds to form organic nitrates, which are not readily analyzed using the techniques presented in this paper. Figure 4 (top) also shows that SMPS volumes and filter masses are similar. The maximum SMPS volume concentration was $130 \mathrm{~nL} \mathrm{~m}^{-3}$, observed at approximately $3 \mathrm{~h}$, when the ozone concentration reached its maximum. The profiles of the inorganic species show the characteristics of a standard volatile organic compound $(\mathrm{VOC}) / \mathrm{NO}_{\mathrm{x}}$ irradiation.

Of greater interest are carbonyls formed during the oxidation, shown in Fig. 4 (bottom) and Table 2. The elution order of products analyzed using HPLC was established from the external hydrazone standards. Formaldehyde, acrolein, and glyoxal formed in the reaction are clearly identified from their retention times. Note that the carbonyl products from the reaction were detected from the first DNPH sample taken at approximately $0.8 \mathrm{~h}$, when NO is still present in the system at relatively high concentrations. Some compounds, including glycolaldehyde, malonaldehyde, 3hydroxypropanaldehyde, and glyceraldehyde, were identified in SOA using PFBHA + BSTFA derivatization (Fig. 1, bottom, and Table 2). According to conventional reaction kinetics, $\mathrm{OH}$ is added to one of the double bonds in 13BD to form an $\mathrm{RO}_{2}$ radical, which oxidizes $\mathrm{NO}$ to $\mathrm{NO}_{2}$, with the resultant alkoxy radical producing a carbonyl product. Liu et al. (1999) reported the formation of several carbonyl compounds, including those observed in this study, under nighttime and/or daytime oxidation of 13BD. Several mechanistic pathways proposed by Liu et al. (1999) likely led to the formation of the major carbonyls observed in our study, including glyoxal, acrolein, glyceraldehyde, and glycolaldehyde. Secondary reactions of glycolaldehyde are known to produce the dicarbonyl compound glyoxal. The importance of the dicarbonyl compounds lies in their possible significance for the formation of organic aerosol, and can lead to the increased production of SOA in an aqueous or non-aqueous aerosol phase (Liu et al., 1999; Carlton et al., 2007; Liggio et al., 2005). In our study, these compounds were detected in the 


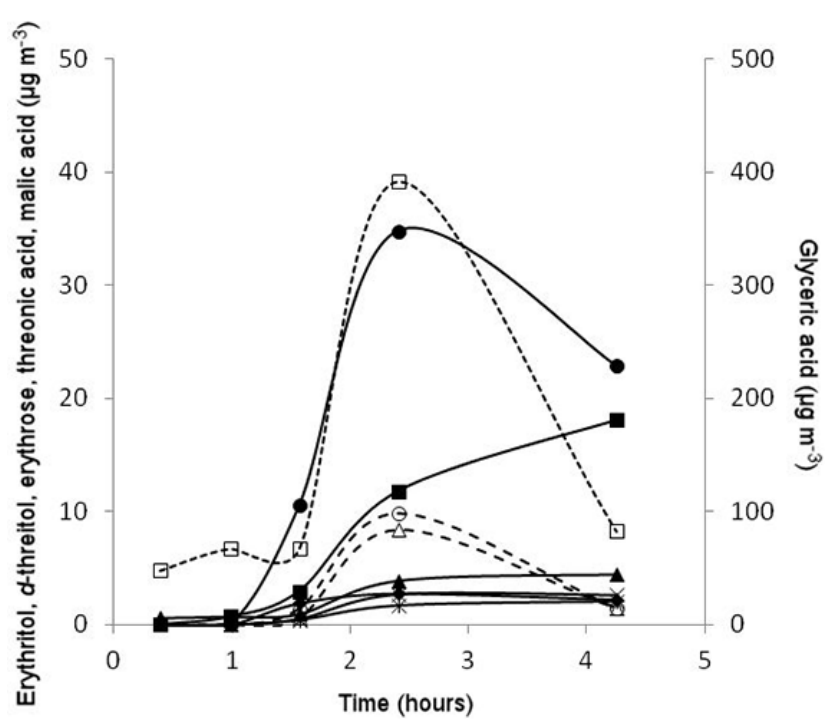

Figure 5. Time profile of gas- and particle-phase products from the oxidation of 13BD in experiment ER442. Quantitative analysis was done as BSTFA derivatives. $d$-threitol was used as a surrogate to quantify erythritol, threonic acid, and malic acid. Particle phase/gas phase: $(\square) /(\square)$ glyceric acid; $(\bullet) /(\circ)$ threonic acid; $(\Delta) /(\triangle)$ erythrose; $(\diamond) /(\diamond)$ malic acid; $(* /)$ threitol.

aerosol phase at high levels, likely due in large part to partitioning from the gas phase.

Gas-phase and SOA components were determined quantitatively for most experiments, and data are shown here for static experiment ER442 using BSTFA derivatization. The quantification method used was similar to methods described by Jaoui et al. (2004, 2005, 2012). This quantitative analysis was based on authentic standards when available and on surrogate compounds when authentic standards could not be found commercially. Calibration factors were determined for authentic and surrogate compounds. Using our best estimates of the calibration factors, concentrations for the main compounds were determined, and are provided in Fig. 4 (bottom) as a function of irradiation time for compounds analyzed using the HPLC system. Figure 5 shows the time evolution of six reaction compounds - glyceric acid, erythritol, threitol, erythrose, threonic acid, and malic acid - in both gas (dashed lines) and particle (solid line) phases. All species reported in Figs. 4 and 5 were analyzed using authentic standards. As can be seen in Figs. 4 and 5, gas and particle compounds analyzed in this study, with the exception of glyceric acid, appear to build up only when $\mathrm{O}_{3}$ starts accumulating in the chamber. This might reflect the importance of ozone chemistry in this system. As $\mathrm{O}_{3}$ starts accumulating in the chamber, the concentration of threonic acid and erythrose in the gas phase (Fig. 4) increased rapidly and then decreased, suggesting that secondary reactions might be occurring. These compounds were also detected in the particle phase, where their concentrations increased steadily, sug-

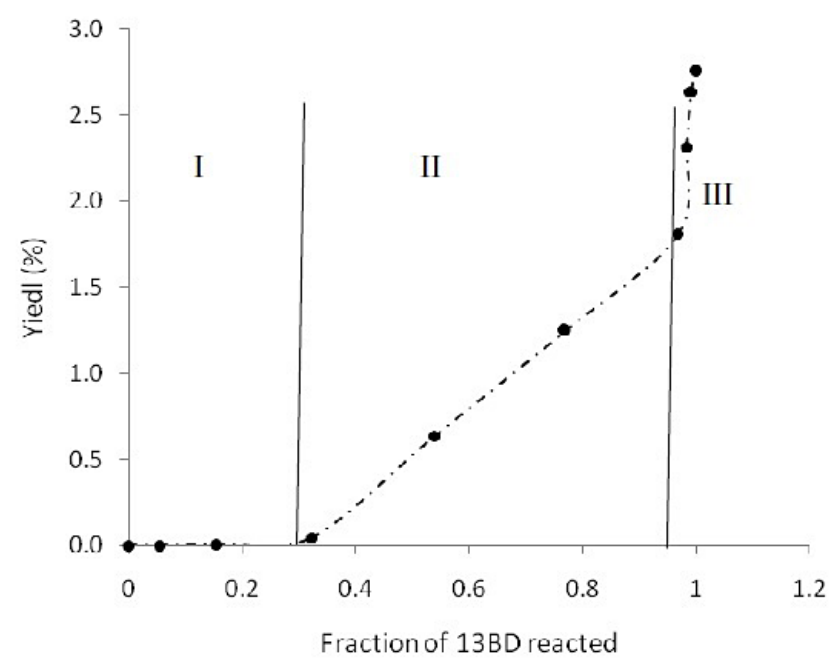

Figure 6. SOA yield as a function of the fraction of 13BD reacted (experiment ER442).

gesting that partitioning of these compounds into the particle phase might also be occurring. Malic acid, $d$-threitol, and erythritol were detected only in the particle phase. Abundant compounds observed in both the gas and particle phases included glyceric acid, with maximum concentrations up to $390 \mu \mathrm{g} \mathrm{m}^{-3}$ in the gas phase and $180 \mu \mathrm{g} \mathrm{m}^{-3}$ in the particle phase. Other compounds were in the $0-10 \mu \mathrm{g} \mathrm{m}^{-3}$ range for the gas phase and the $0-35 \mu \mathrm{g} \mathrm{m}^{-3}$ range for the particle phase. The aerosol yield after all 13BD was consumed was 0.027 for an SOA concentration of $86 \mu \mathrm{g} \mathrm{m}^{-3}$. This yield is very similar to the 0.025 measured by Sato et al. (2008). Figure 6 shows SOA yield as a function of the fraction of 13BD reacted. The aerosol yield started to increase when approximately $30 \%$ of 13BD was reacted, and increased rapidly at approximately $95 \%$. This growth curve can be divided into three regions (Fig. 6). The first region is characteristic of no or very low aerosol formation. After ozone starts building up in the chamber (region II), more aerosol is formed as $13 \mathrm{BD}$ is reacted. After 13BD is completely reacted (region III), aerosol continues to increase, probably due to the oxidation of first- and potentially second- or third-generation products, resulting in a vertical section. $\mathrm{Ng}$ et al. (2006) reported a similar trend for compounds bearing two or more double bonds (isoprene, $\alpha$-terpinene, $y$-terpinene, terpinolene, limonene, myrcene, $\alpha$-humulene, $\beta$-caryophyllene, and linalool).

\subsection{Mechanism of product formation}

Recent studies (Surratt et al., 2010; Sato et al., 2011; Lin et al., 2012, 2013; Pye et al., 2013; Birdsall et al., 2013, 2014) show the importance of epoxide chemistry in isoprene SOA formation. Methacrolein (MAC), methacryloylperoxynitrate (MPAN), and methacrylic acid epoxide (MAE) were proposed as key intermediates in understanding mechanis- 

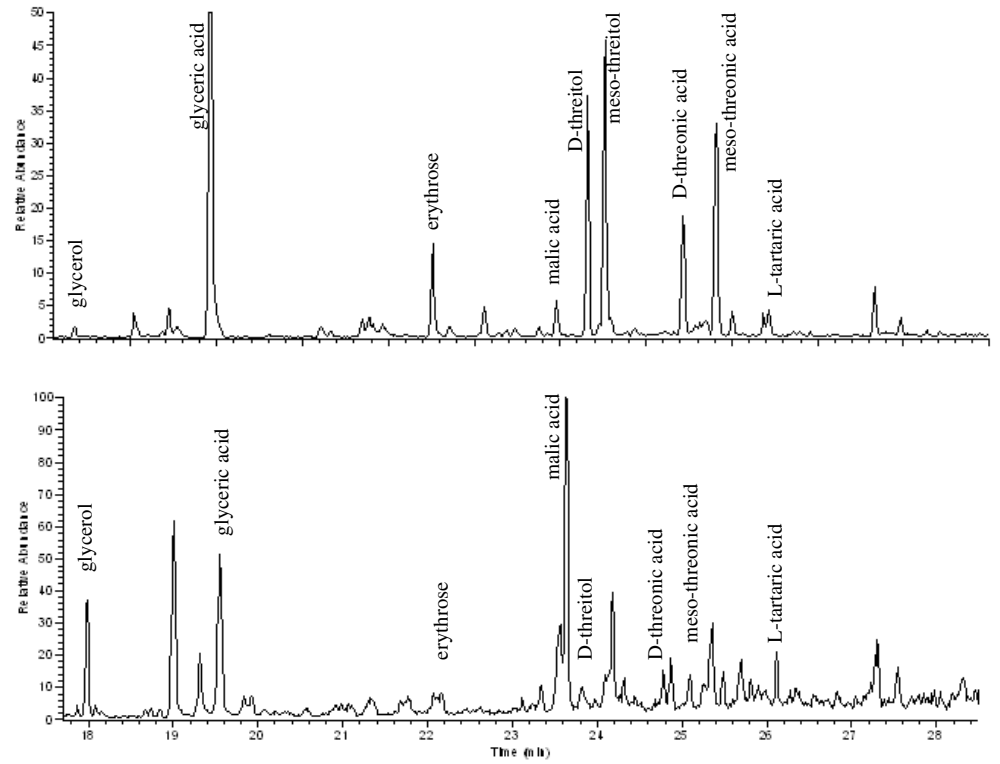

Figure 7. Extracted ion gas chromatograms of organic extracts as BSTFA derivatives from (top) an irradiated 1,3-butadiene/NO ${ }_{\mathrm{x}} /$ air mixture and (bottom) Bakersfield, CA, USA, PM2.5. Extracted ions are 103, 189, 217, 247, 335, 395, and 423.

tic pathways leading to some isoprene reaction products under low or high $\mathrm{NO}_{\mathrm{x}}$ conditions. Of particular importance, species observed recently in isoprene-SOA include 2methylglyceric acid, 2-methyltetrols, 2-methylglyceric acidoligomers, nitric acid esters, and sulfuric acid esters (Edney et al., 2005; Surratt et al., 2007; Szmigielski et al., 2007; Gómez-González et al., 2008; Jaoui et al., 2008; Chan et al., 2010a, b; Nguyen et al., 2011; Hatch et al., 2011a, b; Zhang et al., 2011). For example, MAE formed through MPAN chemistry (Surratt et al., 2010) was proposed as the key precursor to the formation of 2-methylglyceric acid and other oligoesters observed in isoprene aerosol (Lin et al., 2013; Birdsall et al., 2013, 2014). Since isoprene and 1,3-butadiene only differ by one methyl group, it is likely they share similar gas and aerosol phase chemistries that yield SOA. 1,3Butadiene presents a higher degree of symmetry than isoprene, and may lead to a simpler set of mechanistic pathways. The detection in smog chamber experiments of similar end products from isoprene and 13BD oxidation (e.g., methyltetrols vs. tetrols, methylglyceric acid vs. glyceric acid, methacrolein vs. acrolein, methyl-oligoesters vs. oligoesters, etc.) suggests that the atmospheric oxidation of these two hydrocarbons may be similar.

Time profiles from the static experiment (ER442; Table 1) involving 13BD photooxidation in the presence of $\mathrm{NO}_{\mathrm{x}}$ (Figs. 4, 5) show an increase in the concentrations of SOA compounds as ozone concentrations increase. This indicates that ozone reaction is likely involved in the formation of SOA compounds, although under atmospheric conditions, 13BD oxidation with $\mathrm{OH}$ radicals is believed to be dominant. In the following discussion, tentative mechanis- tic pathways leading to some major products observed in the gas and particle phases are shown, based on either $\mathrm{OH}$ and/or ozone reactions. These mechanistic pathways are similar to those reported recently for isoprene. Acrolein, one of the major first-generation products, was proposed to be formed through 13BD reaction with $\mathrm{OH}$ radical, ozone, or $\mathrm{O}(3 \mathrm{P})$, as shown in Scheme 1 (Liu et al., 1999). Other mechanistic pathways leading to some gas-phase products observed in this study, including formaldehyde, glyoxal, glycolaldehyde, butenedial, and malonaldehyde, have been reported (Liu et al., 1999) through either $\mathrm{O}_{3}$ or $\mathrm{OH}$ reactions with $13 \mathrm{BD}$, and are not presented here.

Recent studies show that epoxide species (e.g., IEPOX low $\mathrm{NO}_{\mathrm{x}}$ - and MAE - high $\mathrm{NO}_{\mathrm{x}}$ - for isoprene) play an important role in understanding SOA formation (Paulot et al., 2009; Lin et al., 2013; Birdsall et al., 2014; Nguyen et al., 2014). Similar to isoprene chemistry, two epoxides (acrylic acid epoxide (AAE) and 2,3-epoxy-1,4-butanediol - BEPOX) formed in the gas phase through the reaction of 13BD with $\mathrm{OH}$ radicals are proposed as key intermediates in SOA formation. Scheme 2 shows reaction pathways leading to the formation of acrylic acid epoxide (AAE: right side) and 2,3epoxy-1,4-butanediol (BEPOX: left side) under high and low $\mathrm{NO}_{\mathrm{x}}$ conditions, respectively. These mechanistic pathways are similar to those proposed for isoprene (Paulot et al., 2009; Surratt et al., 2010; Lin et al., 2013; Nguyen et al., 2014; Birdsall et al., 2014) for the formation of MAE and IEPOX, respectively. Under low $\mathrm{NO}_{\mathrm{x}}$ conditions, BEPOX is proposed as being formed through $\mathrm{OH}$ radical addition to one of the external positions of the double bonds to form hydroxyhydroperoxide (13BDOOH). Subsequent addition of $\mathrm{OH}$ radi- 


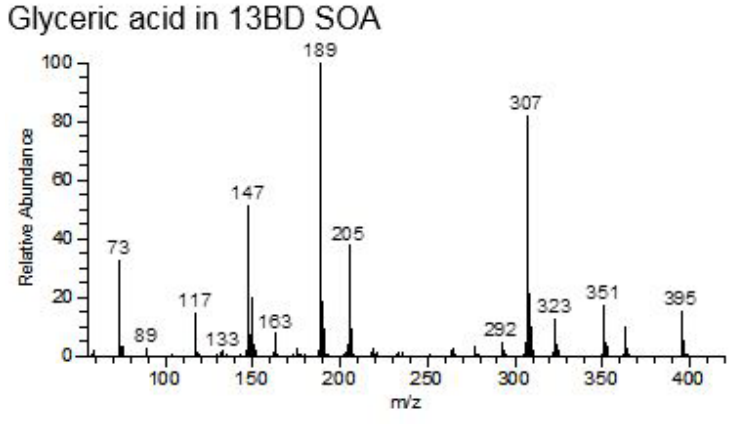

Glyceric acid in Bakersfield PM2.5

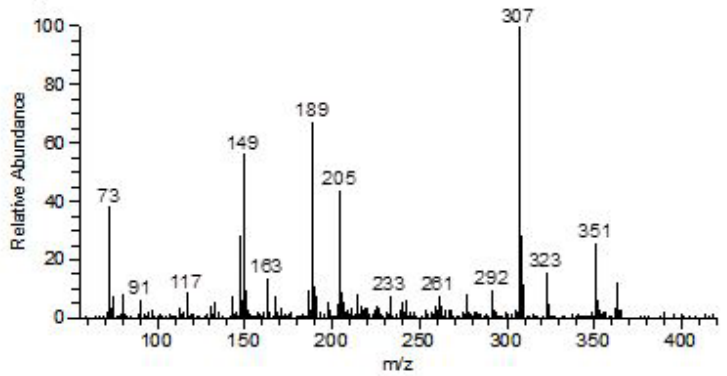

Erythrose in 13BD SOA

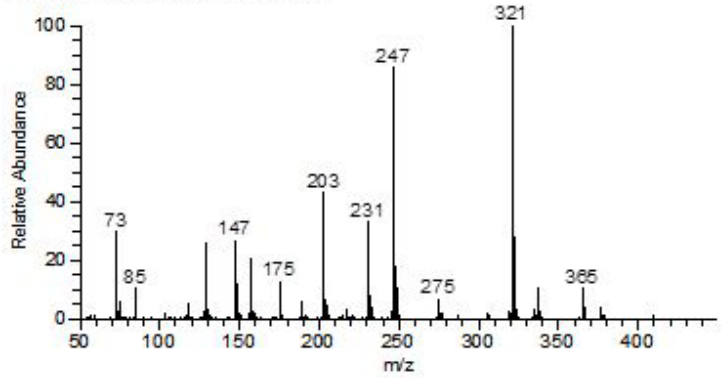

Erythrose in Bakersfield PM2.5

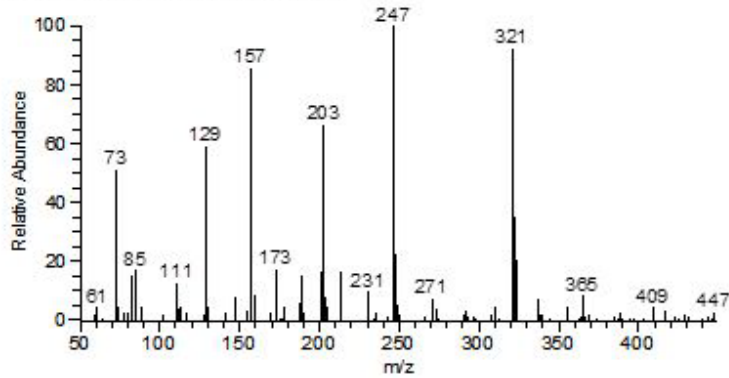

D-Threitol in 13BD SOA

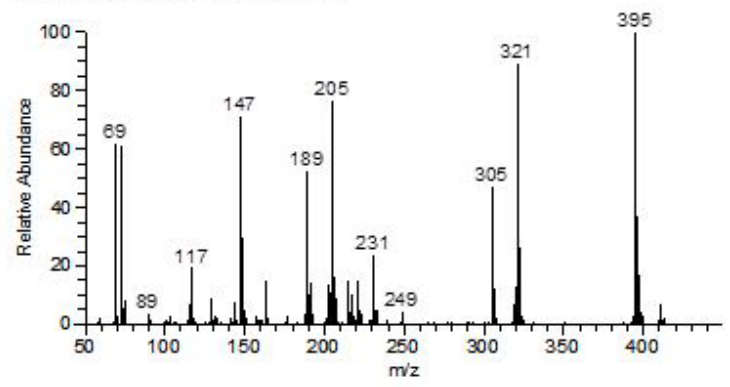

D-Threitol in Bakersfield PM2.5

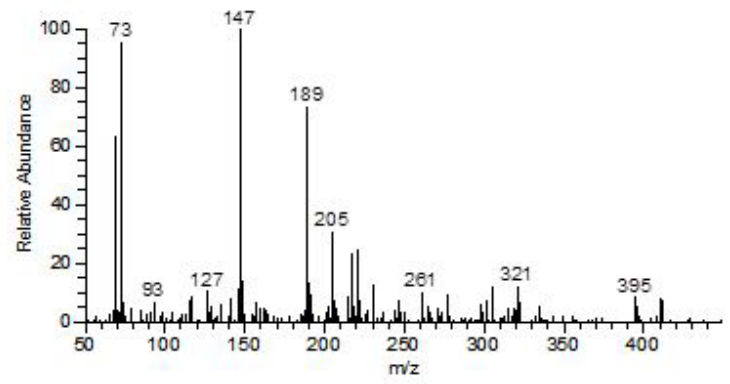

Threonic acid in 13BD SOA

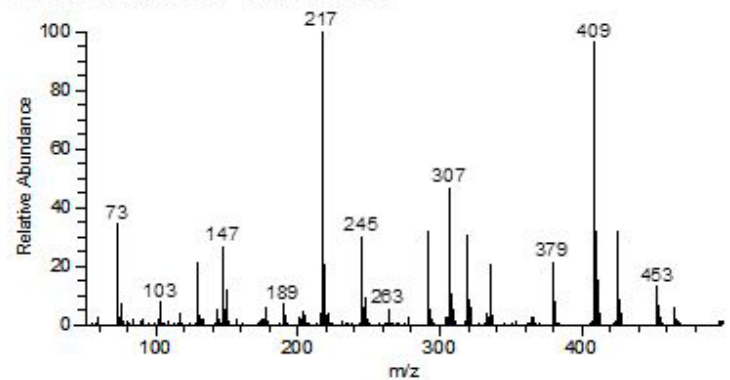

Threonic acid in Bakersfield $\mathrm{PM}_{2.5}$

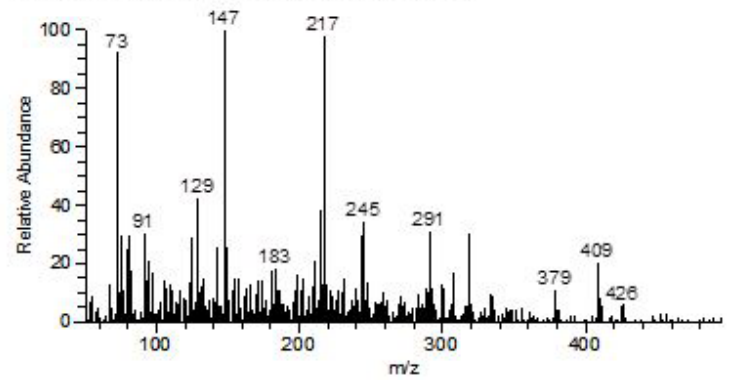

Figure 8. CI mass spectra of some organic compounds present in irradiated 1,3-butadiene/ $\mathrm{NO}_{\mathrm{x}} /$ air and in ambient $\mathrm{PM}_{2.5}$ extracts originating from a field sample from the western US (Bakersfield, CA).

cals to the other double bond of 13BDOOH yields dihydroxyepoxide (BEPOX), as shown on the left side (Scheme 2). In addition, 1,4-anhydroerythritol compound was detected in 13BD SOA (Table 2). This compound is similar to 3methyldihydroxytetrahyrofurans formed from the oxidation of isoprene through IEPOX oxidation via acid-catalyzed rearrangement of sulfate aerosol (Zhang et al., 2011; Lin et al., 2012). 1,4-Anhydroerythritol observed here may be formed through similar reactions starting from BEPOX, and presents further evidence that BEPOX is formed from the oxidation of 13-BD and plays a role in SOA formation. In the presence of $\mathrm{NO}_{\mathrm{x}}$, Scheme 2 (right side) shows the formation of acrolein through 13BD reaction with $\mathrm{OH}$ radicals yielding hydroxyperoxy radicals, then acrolein (see also Scheme 1). Acrolein reacts with $\mathrm{OH}$ radidals, and in the presence of $\mathrm{NO}$, yields the formation of APAN (Scheme 2: right side). Similar to MPAN (Lin et al., 2013), APAN is proposed as reacting with $\mathrm{OH}$ radicals, leading to AAE compounds. 


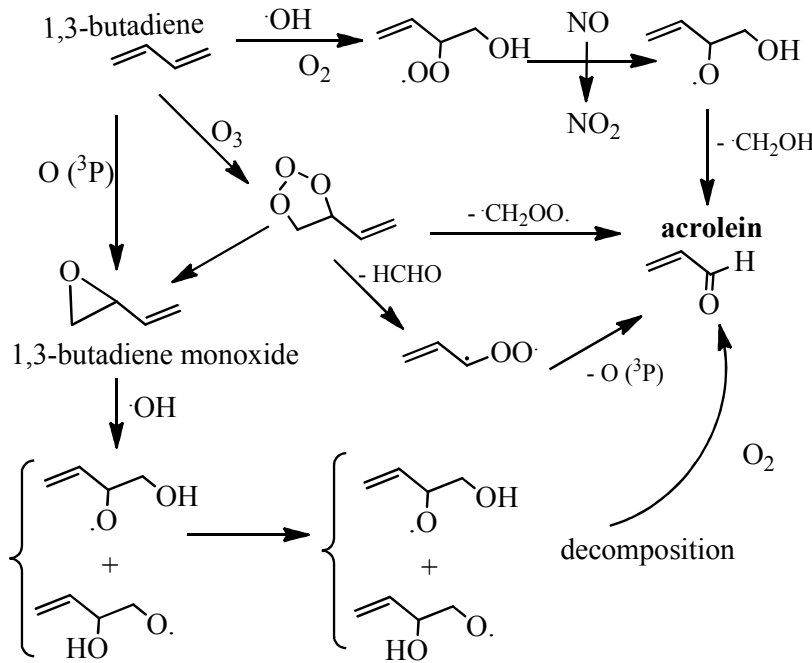

Scheme 1. Acrolein formation from 1,3-butadiene oxidation.

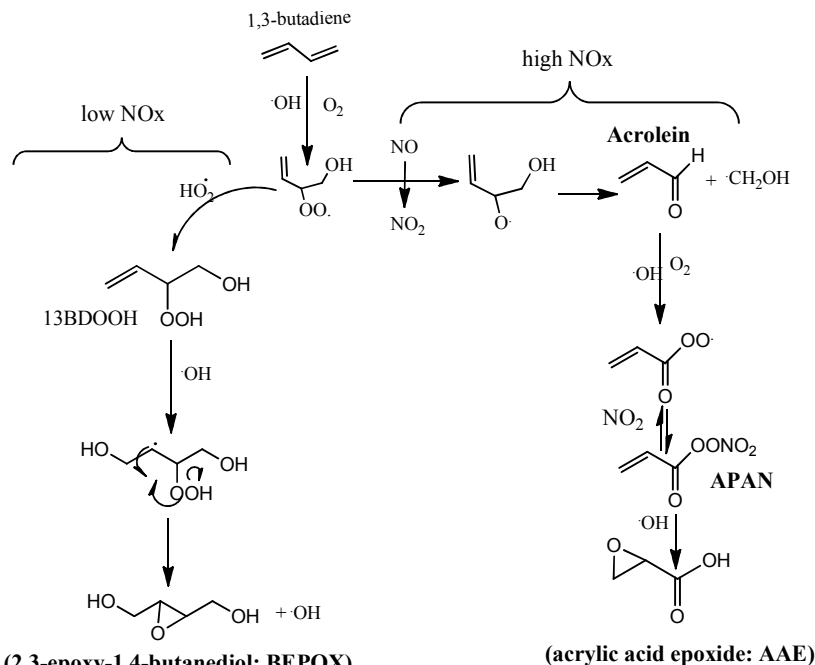

(2,3-epoxy-1,4-butanediol: BEPOX)

(acrylic acid epoxide: AAE)

Scheme 2. Proposed mechanism for AAE and BEPOX formation from 1,3-butadiene oxidation.

Mass spectra obtained from GC-MS analysis of SOA originating from experiments involving $\mathrm{NO}_{\mathrm{x}}$ show the presence of a series of monomeric compounds as well as oligoesters structurally related to these monomers (Table 2). Although important advances have been made recently for isoprene chemistry in understanding key intermediate species (epoxides) leading to SOA formation (Birdsall et al., 2014), the conditions necessary for their formation (e.g., acidity, water content, inorganic ions, etc.) and the specific chemical mechanisms by which these compounds are formed remain unknown. Lin et al. (2013) and Birdsall et al. (2014) show the importance of MAE in the formation of methylglyceric acid as well as a wide range of oligoesters structurally related to 2-methylglyceric acid. For oligoester formation, Birdsall et al. (2014) presented data suggesting that acid-

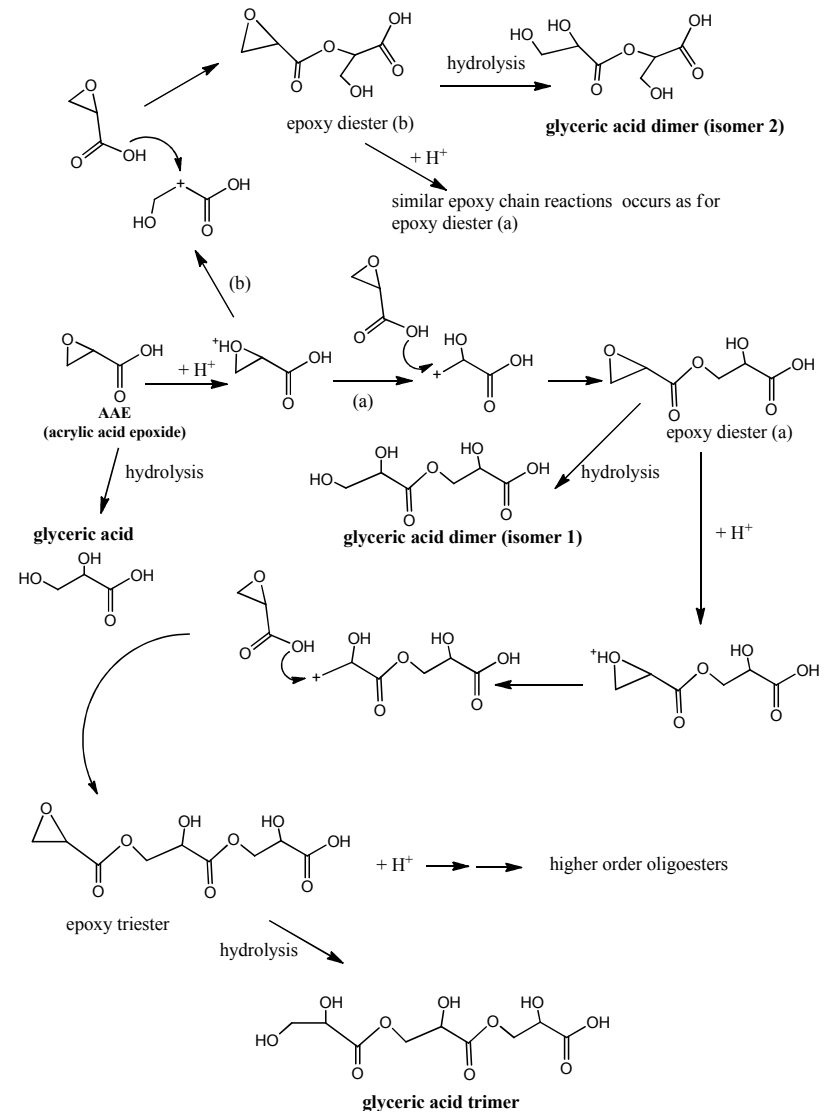

Scheme 3. Proposed mechanism for AAE oligomerization via epoxy chain reactions leading to glyceric acid and glyceric acid oligoesters.

catalyzed nucleophilic addition of MAE is kinetically feasible in the atmosphere, mainly under acidic conditions, but much slower than the epoxide chain reaction. In addition, Birdsall et al. (2014) show that a series of nucleophile reactions may occur in the atmosphere, including self-reaction of MAE as well as MAE reaction with other nucleophilic compounds (water, acids, and alcohols). In this study, a series of oligoesters were observed, and their formation may follow similar mechanistic pathways to those proposed by Birdsall et al. (2014) for isoprene reaction. Scheme 3 shows a proposed mechanism for AAE oligomerization via epoxy chain reaction. In the presence of $\mathrm{H}^{+}$, AAE undergoes nucleophilic addition, leading to a series of epoxy glyceric acid oligomers. Two pathways $(a, b)$ are shown in Scheme 3 , showing the formation of two isomers (i.e., glyceric acid dimer 1, and glyceric acid dimer 2). Each epoxy compound may undergo hydrolysis leading to the corresponding monomer or oligomer.

The detection in the aerosol phase of a series of oligoesters with structures characteristic of a combination of an alcohol compound and an acid compound (Table 2) suggests that reactions in the aerosol phase between monomer compounds bearing alcohol and acid groups may occur. Recent work by 


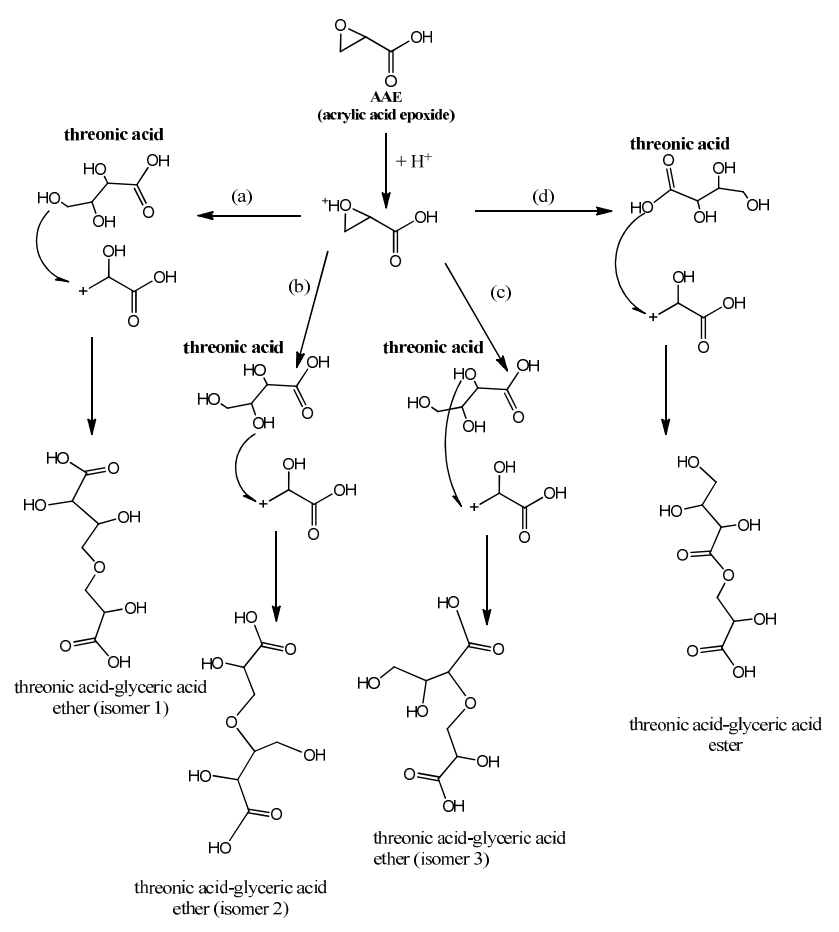

Scheme 4. Proposed mechanism for AAE + threonic acid via nucleophilic addition reaction.

Birdsall et al. (2013) shows that classical esterification reactions involving reactions of organic acid and alcohol under atmospheric conditions are too slow to occur, and cannot account for all the oligoesters observed in chamber experiments. Based on this work and prior work (Surratt et al., 2010; Lin et al., 2013), Birdsall et al. (2014) provided evidence that nucleophilic reaction between MAE and a series of nucleophilic compounds yields a series of oligoesters including ethers, esters, and diols. By analogy to MAE, we proposed in this study similar nucleophilic reactions between AAE and a series of nucleophilic products observed in this study, leading to ethers (3 isomers) and one ester (Table 2) (e.g., acids - oxalic acid, malic acid, threonic acid - and alcohols - tetrols, glycerol, etc.). As an example, Scheme 4 shows the proposed mechanism of AAE and threonic acid reaction via nucleophilic addition. The nucleophilic addition of threonic acid, a trihydroxy acid, to AAE involves all three alcoholic $\mathrm{OH}$ groups, leading to the formation of three ether compounds (pathways a, b, and c), as well as the carboxylic $\mathrm{COOH}$ group, leading to the formation of an ester (pathway d).

None of these oligoesters was detected in ambient samples analyzed using the same derivatization techniques, suggesting that oligoesters may be formed mainly under laboratory conditions where high concentrations of AAE and other nucleophile species are present. In addition, under atmospheric conditions, water and other non-epoxide nucleophile compounds may limit the formation of oligoesters due to a competitive hydrolysis pathway when epoxides are formed (Scheme 3). This is consistent with the work reported by Birdsall et al. (2014) involving MAE nucleophilic reactions.

\subsection{Field measurements}

Some organic compounds observed in the gas phase in laboratory samples are also present in ambient air. High concentrations of formaldehyde, glyoxal, acrolein, and APAN were observed from 13BD oxidation. Data reported in the literature show that these compounds are ubiquitous in urban ambient samples and suggest that 13BD might be a contributing source of these compounds in areas dominated by 13BD emission rates. In addition, the uptake of some of these compounds (e.g., glyoxal) in the aerosol phase followed by heterogeneous sulfur chemistry can lead to SOA formation (Carlton et al., 2007; Liggio et al., 2005; Chan et al., 2010a, b). The role of APAN in ambient SOA formation could be important, and might follow similar chemistry to MPAN, which only recently was found to play a role in SOA formation from isoprene (Tanimoto and Akimoto, 2001; Surratt et al., 2010).

Of great interest are eight organic compounds observed in both laboratory and field sample particle phase. These compounds are shown in Fig. 7 in an extracted ion chromatogram of a $\mathrm{PM}_{2.5}$ sample collected in Bakersfield, CA (Liu et al., 2012). A comparison of mass spectra from the laboratory sample with those measured at the field site is shown in Fig. 8 for glyceric acid, $d$-threitol, erythrose, and threonic acid. Glycerol, glyceric acid, malic acid, threitol, erythritol, and tartaric acid were previously observed in ambient samples, and have been thought to have originated from several sources, although their origin is still associated with high uncertainty. From this work, it now appears that these compounds could be generated in the atmosphere from the oxidation of 13BD. Additionally, glyceric acid, threitol, erythritol, erythrose, and threonic acid observed in this study appear to have originated only from 13BD. An analysis of chromatograms obtained from chamber experiments conducted in our laboratory involving the oxidation of biogenic (e.g., isoprene, monoterpenes, sesquiterpenes, 2-methyl-3-buten2-ol), aromatic (e.g., toluene, 1,3,5-trimethylbenzene, benzene), and polycyclic aromatic hydrocarbons (PAHs) (e.g., naphthalene) shows that these compounds were not detected in these systems using the same experimental analysis. In fact, in selected ambient samples, particularly those collected in an urban environment, glyceric acid, threitol, erythritol, erythrose, and threonic acid have been detected in this study. Although the nine compounds were detected in several field samples analyzed by our group (e.g., the Cleveland Multiple Air Pollutant Study - CMAPS - field study, Piletic et al., 2013; Midwestern United States, Lewandowski et al., 2007, 2008), the field samples analyzed for this paper focus on 27 samples collected in Bakersfield, CA, between 19 May 2010 
and 26 June 2010. The concentrations of malic acid, glyceric acid, erythritol, erythrose, and threonic acid ( $d$-threonic acid + meso-threonic acid) were determined in ambient samples using the same method used for static experiment ER442. The total $\mathrm{PM}_{2.5}$ mass in the atmosphere during this sampling period ranged from 0.06 to $1.17 \mu \mathrm{g} \mathrm{m}^{-3}$. The concentrations for individual compounds ranged from 0 to $14.1 \mathrm{ng} \mathrm{m}^{-3}$. These values are typical of the range of values often seen for individual compounds detected in ambient samples.

\section{Summary}

In the present manuscript, laboratory experiments were conducted to investigate SOA formation from the oxidation of 1,3-butadiene in the presence and absence of $\mathrm{NO}_{\mathrm{x}}$. Chamber aerosol collected under these conditions has been analyzed for organic mass to organic carbon ratio, effective enthalpy of vaporization, and aerosol yield. In addition, the chemical composition of the gas phase and SOA was analyzed using derivative-based methods followed by gas chromatographymass spectrometry or high-performance liquid chromatography analysis of the derivative compounds. More than 60 oxygenated organic compounds in the gas and particle phases were observed, of which 31 organic monomers were tentatively identified. The major products identified are glyceric acid, $d$-threitol, erythritol, $d$-threonic acid, meso-threonic acid, erythrose, malic acid, tartaric acid, and carbonyls, including glycolaldehyde, glyoxal, acrolein, malonaldehyde, glyceraldehyde, and peroxyacryloyl nitrate (APAN).

Two epoxide compounds, BEPOX and AAE, are proposed in this study as key intermediates for the formation of an important class of 13BD-derived compounds, including glyceric acid and oligoesters found in SOA. Similar to isoprene oxidation (Birdsall et al., 2014), the mechanism proposed is based on epoxide chain reaction of AAE, as well as AAE reaction with a number of nucleophile species, including water, carboxylic acids and alcohols. The BEPOX channel is also an important pathway leading to ambient SOA formation. However, none of these oligoesters was detected in ambient samples, suggesting that oligoesters may be formed mainly under laboratory conditions where high concentrations of AAE and other nucleophile species are present. These oligoesters under ambient conditions may be unstable, and, after their decomposition, could be possible sources of glyceric acid, threonic acid, and tetrols found in ambient aerosol.

The results of this study potentially have atmospheric implications for areas impacted by 1,3-butadiene oxidation, and contribute to understanding the formation of ambient SOA from small anthropogenic precursors. For instance, several compounds were detected and identified in both field and smog chamber SOA (e.g., malic acid, glyceric acid, erythritol, erythrose, and threonic acid), and suggest that they might be responsible for the formation and/or growth of the aerosol in regions impacted by $13 \mathrm{BD}$ emission. The presence of nucleophile compounds (acids, alcohols, epoxides) and aldehyde, including dicarbonyls (e.g., glyoxal), and their potential for heterogeneous and multiphase processes, are also very interesting. However, in the absence of authentic standards, it is difficult to quantify the contribution of SOA originating from 13BD to ambient $\mathrm{PM}_{2.5}$ accurately. Due to the health risks associated with 13BD and its reaction products, this work indicates the importance of increasing the inclusion of detailed chemistry of 13BD in photochemical models and local, regional, and global models used to investigate ozone and SOA formation and health concerns in rural and urban areas.

Acknowledgements. The US Environmental Protection Agency through its Office of Research and Development funded and collaborated in the research described here under contract EPD-10-070 to Alion Science and Technology. The manuscript has been subjected to external peer review and has been cleared for publication. Mention of trade names or commercial products does not constitute endorsement or recommendation for use.

Edited by: J. Roberts

\section{References}

Acquavella, J. F.: Butadiene epidemiology: a summary of results and outstanding issues, Toxicology, 113, 148-156, 1996.

Angove, D. E., Fookes, C. J. R., Hynes, R. G., Walters, C. K., and Azzi, M.: The characterisation of secondary organic aerosol formed during the photodecomposition of 1,3-butadiene in air containing nitric oxide, Atmos. Environ., 40, 4597-4607, 2006.

Anttinen-Klemetti, T., Vaaranrinta, R., Mutanen, P., and Peltonen, K.: Inhalation exposure to 1,3-butadiene and styrene in styrene-butadiene copolymer production, Int. J. Hyg. Envir. Heal., 209, 151-158, 2006.

Atkinson, R.: Atmospheric chemistry of VOCs and $\mathrm{NO}_{\mathrm{x}}$, Atmos. Environ., 34, 2063-2101, doi:10.1016/S1352-2310(99)00460-4, 2000.

Berndt, T. and Böge, O.: Atmospheric reaction of $\mathrm{OH}$ radicals with 1,3-butadiene and 4-hydroxy-2-butenal, J. Phys. Chem. A, 111, 12099-12105, 2007.

Birdsall, A. W., Zentner, C. A., and Elrod, M. J.: Study of the kinetics and equilibria of the oligomerization reactions of 2-methylglyceric acid, Atmos. Chem. Phys., 13, 3097-3109, doi:10.5194/acp-13-3097-2013, 2013.

Birdsall, A. W., Miner, C. R., Mael, L. E., and Elrod, M. J.: Mechanistic study of secondary organic aerosol components formed from nucleophilic addition reactions of methacrylic acid epoxide, Atmos. Chem. Phys. Discuss., 14, 19917-19954, 2014, http://www.atmos-chem-phys-discuss.net/14/19917/2014/.

Carlton, A. G., Turpin, B. J., Altieri, K. E., Seitzinger, S., Reff, A., Lim, H.-J., and Ervens, B.: Atmospheric oxalic acid and SOA production from glyoxal: results of aqueous photooxidation experiments, Atmos. Environ., 41, 7588-7602, 2007.

Chan, A.W. H., Chan, M. N., Surratt, J. D., Chhabra, P. S., Loza, C. L., Crounse, J. D., Yee, L. D., Flagan, R. C., Wennberg, P. 
O., and Seinfeld, J. H.: Role of aldehyde chemistry and $\mathrm{NO}_{\mathrm{x}}$ concentrations in secondary organic aerosol formation, Atmos. Chem. Phys., 10, 7169-7188, 25 doi:10.5194/acp-10-7169-2010, 2010a.

Chan, M. N., Surratt, J. D., Claeys, M., Edgerton, E. S., Tanner, R. L., Shaw, S. L., Zheng, M., Knipping, E. M., Eddingsaas, N. C., Wennberg, P. O., and Seinfeld, J. H.: Characterization and quantification of isoprene-derived epoxydiols in ambient aerosol in the southeastern United States, Environ. Sci. Technol., 44, 45904596, 2010b.

Charlson, R. J., Schwartz, S. E., Hales, J. M., Cess, R. D., Coakley Jr., J. A., Hansen, J. E., and Hoffman, D. J.: Climate forcing by anthropogenic aerosols, Science, 255, 423-430, doi:10.1126/science.255.5043.423, 1992.

Claeys, M., Graham, B., Vas, G., Wang, W., Vermeylen, R., Pashynska, V., Cafmeyer, J., Guyon, P., Andreae, M. O., Artaxo, P., and Maenhaut, W.: Formation of secondary organic aerosols through photooxidation of isoprene, Science, 303, 1173-1176, 2004.

Claeys, M., Kourtchev, I., Pashynska, V., Vas, G., Vermeylen, R., Wang, W., Cafmeyer, J., Chi, X., Artaxo, P., Andreae, M. O., and Maenhaut, W.: Polar organic marker compounds in atmospheric aerosols during the LBA-SMOCC 2002 biomass burning experiment in Rondônia, Brazil: sources and source processes, time series, diel variations and size distributions, Atmos. Chem. Phys., 10, 9319-9331, doi:10.5194/acp-10-9319-2010, 2010.

Decesari, S., Fuzzi, S., Facchini, M. C., Mircea, M., Emblico, L., Cavalli, F., Maenhaut, W., Chi, X., Schkolnik, G., Falkovich, A., Rudich, Y., Claeys, M., Pashynska, V., Vas, G., Kourtchev, I., Vermeylen, R., Hoffer, A., Andreae, M. O., Tagliavini, E., Moretti, F., and Artaxo, P.: Characterization of the organic composition of aerosols from Rondônia, Brazil, during the LBASMOCC 2002 experiment and its representation through model compounds, Atmos. Chem. Phys., 6, 375-402, doi:10.5194/acp6-375-2006, 2006.

Dollard, G. J., Dore, C. J., and Jenkin, M. E.: Ambient concentrations of 1,3-butadiene in the UK, Chem. Biol. Interact., 135, 177206, 2001

Doyle, M., Sexton, K. G., Jeffries, H., Bridge, K., and Jaspers, I.: Effects of 1,3-butadiene, isoprene, and their photochemical degradation products on human lung cells, Environ Health Pers., 112, 1488-1495, 2004.

Duffy, B. L. and Nelson, P. F.: Exposure to emissions of 1,3butadiene and benzene in the cabins of moving motor vehicles and buses in Sydney, Australia, Atmos. Environ., 31, 3877-3885, 1997.

Eatough, D. J., Hansen, L. D., and Lewis, E. A.: The chemical characterization of environmental tobacco smoke, Environ. Technol., 11, 1071-1085, 1990.

Edney, E. O., Kleindienst, T. E., Jaoui, M., Lewandowski, M., Offenberg, J. H., Wang, W., and Claeys, M.: Formation of 2-methyl tetrols and 2-methylglyceric acid in secondary organic aerosol from laboratory irradiated isoprene $/ \mathrm{NO}_{\mathrm{x}} / \mathrm{SO}_{2}$ /air mixtures and their detection in ambient $\mathrm{PM}_{2.5}$ samples collected in the eastern United States, Atmos. Environ., 39, 5281-5289, 2005.

Ekström, S., Nozière, B., and Hansson, H.-C.: The Cloud Condensation Nuclei $(\mathrm{CCN})$ properties of 2-methyltetrols and $\mathrm{C} 3-$ C6 polyols from osmolality and surface tension measurements, Atmos. Chem. Phys., 9, 973-980, doi:10.5194/acp-9-973-2009, 2009.
Fu, P. Q., Kawamura, K., Pavuluri, C. M., Swaminathan, T., and Chen, J.: Molecular characterization of urban organic aerosol in tropical India: contributions of primary emissions and secondary photooxidation, Atmos. Chem. Phys., 10, 2663-2689, doi:10.5194/acp-10-2663-2010, 2010.

Gómez-González, Y., Surratt, J. D., Cuyckens, F., Szmigielski, R., Vermeylen, R., Jaoui, M., Lewandowski, M., Offenberg, J. H., Kleindienst, T. E., Edney, E. O., Blockhuys, F., Van Alsenoy, C., Maenhaut, W., and Claeys, M.: Characterization of organosulfates from the photooxidation of isoprene and unsaturated fatty acids in ambient aerosol using liquid chromatography/(-) electrospray ionization mass spectrometry, J. Mass Spectrom., 43, 371-382, doi:10.1002/jms.1329, 2008.

Grosjean, D. and Seinfeld, J. H.: Parameterization of the formation potential of secondary organic aerosols, Atmos. Environ., 23, 1733-1747, 1989.

Hallquist, M., Wenger, J. C., Baltensperger, U., Rudich, Y., Simpson, D., Claeys, M., Dommen, J., Donahue, N. M., George, C., Goldstein, A. H., Hamilton, J. F., Herrmann, H., Hoffmann, T., Iinuma, Y., Jang, M., Jenkin, M. E., Jimenez, J. L., Kiendler-Scharr, A., Maenhaut, W., McFiggans, G., Mentel, Th. F., Monod, A., Prévôt, A. S. H., Seinfeld, J. H., Surratt, J. D., Szmigielski, R., and Wildt, J.: The formation, properties and impact of secondary organic aerosol: current and emerging issues, Atmos. Chem. Phys., 9, 5155-5236, doi:10.5194/acp-9-51552009, 2009.

Hatch, L. E., Creamean, J. M., Ault, A. P., Surratt, J. D., Chan, M. N., Seinfeld, J. H., Edgerton, E. S., Su, Y., and Prather, K. A.: Measurements of isoprene-derived organosul fates in ambient aerosols by aerosol time-of-flight mass spectrometry - Part 1: Single particle atmospheric observations in Atlanta, Environ. Sci. Technol., 45, 5105-5111, doi:10.1021/es103944a, 2011a.

Hatch, L. E., Creamean, J. M., Ault, A. P., Surratt, J. D., Chan, M. N., Seinfeld, J. H., Edgerton, E. S., Su, Y., and Prather, K. A.: Measurements of isoprene-derived organosulfates in ambient aerosols by aerosol time-of-flight mass spectrometry - Part 2: Temporal variability and formation mechanisms, Environ. Sci. Technol., 45, 8648-8655, doi:10.1021/es2011836, $2011 \mathrm{~b}$.

Hurst, H. E.: Toxicology of 1,3-butadiene, chloroprene, and isoprene, Rev. Environ. Contam. T., 189, 131-179, 2007.

Jaoui, M., Kleindienst, T. E., Lewandowski, M., and Edney, E. O.: Identification and quantification of aerosol polar oxygenated compounds bearing carboxylic or hydroxyl groups. 1. Method development, Anal. Chem., 76, 4765-4778, 2004.

Jaoui, M., Kleindienst, T. E., Lewandowski, M., Offenberg, J. H., and Edney, E. O.: Identification and quantification of aerosol polar oxygenated compounds bearing carboxylic or hydroxyl groups. 2. Organic tracer compounds from monoterpenes, Environ. Sci. Technol., 39, 5661-5673, 2005.

Jaoui, M., Edney, E. O., Kleindienst, T. E., Lewandowski, M., Offenberg, J. H., Surratt, J. D., and Seinfeld, J. H.: Formation of secondary organic aerosol from irradiated $\alpha$-pinene/toluene/ $/ \mathrm{NO}_{\mathrm{x}}$ mixtures and the effect of isoprene and sulfur dioxide, J. Geophys. Res., 113, D09303 doi:10.1029/2007jd009426, 2008.

Jaoui, M., Kleindienst, T. E., Offenberg, J. H., Lewandowski, M., and Lonneman, W. A.: SOA formation from the atmospheric oxidation of 2-methyl-3-buten-2-ol and its implications for $\mathrm{PM}_{2.5}$, Atmos. Chem. Phys., 12, 2173-2188, doi:10.5194/acp-12-21732012, 2012. 
Kanakidou, M., Seinfeld, J. H., Pandis, S. N., Barnes, I., Dentener, F. J., Facchini, M. C., Van Dingenen, R., Ervens, B., Nenes, A., Nielsen, C. J., Swietlicki, E., Putaud, J. P., Balkanski, Y., Fuzzi, S., Horth, J., Moortgat, G. K., Winterhalter, R., Myhre, C. E. L., Tsigaridis, K., Vignati, E., Stephanou, E. G., and Wilson, J.: Organic aerosol and global climate modelling: a review, Atmos. Chem. Phys., 5, 1053-1123, doi:10.5194/acp-51053-2005, 2005.

Kleindienst, T. E., Edney, E. O., Lewandowski, M., Offenberg, J. H., and Jaoui, M.: Secondary organic carbon and aerosol yields from the irradiations of isoprene and alpha-pinene in the presence of $\mathrm{NO}_{\mathrm{x}}$ and $\mathrm{SO}_{2}$, Environ. Sci. Technol., 40, 3807-3812, 2006.

Kleindienst, T. E., Jaoui, M., Lewandowski, M., Offenberg, J. H., Lewis, C. W., Bhave, P. V., and Edney, E. O.: Estimates of the contributions of biogenic and anthropogenic hydrocarbons to secondary organic aerosol at a southeastern US location, Atmos. Environ., 41, 8288-8300, 2007.

Kleindienst, T. E., Lewandowski, M., Offenberg, J. H., Jaoui, M., and Edney, E. O.: The formation of secondary organic aerosol from the isoprene $+\mathrm{OH}$ reaction in the absence of $\mathrm{NO}_{\mathrm{x}}$, Atmos. Chem. Phys., 9, 6541-6558, doi:10.5194/acp-9-6541-2009, 2009.

Kleindienst, T. E., Lewandowski, M., Offenberg, J. H., Edney, E. O., Jaoui, M., Zheng, M., Ding, X., and Edgerton, E. S.: Contribution of primary and secondary sources to organic aerosol and $\mathrm{PM}_{2.5}$ at SEARCH network sites, JAPCA J. Air Waste Ma., 60, 1388 1399, 2010.

Kramp, F. and Paulson, S. E.: The gas phase reaction of ozone with 1,3-butadiene: formation yields of some toxic products, Atmos. Environ., 34, 35-43, 2000.

Kroll, J. H., Ng, N. L., Murphy, S. M., Flagan, R. C., and Seinfeld, J. H.: Secondary organic aerosol formation from isoprene photooxidation, Environ. Sci. Technol., 40, 1869-1877, 2006.

Lewandowski, M., Jaoui, M., Kleindienst, T. E., Offenberg, J. H., and Edney, E. O.: Composition of $\mathrm{PM}_{2.5}$ during the summer of 2003 in Research Triangle Park, North Carolina, Atmos. Environ., 41, 4073-4083, 2007.

Lewandowski, M., Jaoui, M., Offenberg, J. H., Kleindienst, T. E., Edney, E. O., Sheesley, R. J., and Schauer, J. J.: Primary and secondary contributions to ambient PM in the midwestern United States, Environ. Sci. Technol., 42, 3303-3309, 2008.

Lewandowski, M., Jaoui, Offenberg, J. H., Krug, J., and Kleindienst, T. E.: Atmospheric oxidation of 1, 3-butadiene: 2. Influence of aerosol acidity and relative humidity, Atmos. Chem. Phys. Discuss., accepted, 2014.

Liggio, J., Li, S.-M., and McLaren, R.: Reactive uptake of glyoxal by particulate matter, J. Geophys. Res.-Atmos., 110, D10304, doi:10.1029/2004JD005113, 2005.

Lin, Y.-H., Zhang, Z., Docherty, K. S., Zhang, H., Budisulistiorini, S. H., Rubitschun, C. L., Shaw, S. L., Knipping, E. M., Edgerton, E. S., Kleindienst, T. E., Gold, A., and Surratt, J. D.: Isoprene epoxydiols as precursors to secondary organic aerosol formation: Acid-catalyzed reactive uptake studies with authentic compounds, Environ. Sci. Technol., 46, 250-258, 2012.

Lin, Y.-H., Zhang, H., Pye, H. O. T., Zhang, Z., Marth, W. J., Park, S., Arashiro, M., Cui, T., Budisulistiorini, S. H., Sexton, K. G., Vizuete, W., Xie, Y., Luecken, D. J., Piletic, I. R., Edney, E. O., Bartolotti, L. J., Gold, A., and Surratt, J. D.: Epoxide as a precursor to secondary organic aerosol formation from isoprene pho- tooxidation in the presence of nitrogen oxides, P. Natl. Acad. Sci USA, 110, 6718-6723, doi:10.1073/pnas.1221150110, 2013.

Liu, S., Ahlm, L., Day, D. A., Russell, L. M., Zhao, Y., Gentner, D. R., Weber, R. J., Goldstein, A. H., Jaoui, M., Offenberg, J. H., Kleindienst, T. E., Rubitschun, C., Surratt, J. D., Sheesley, R. J., and Scheller, S.: Secondary organic aerosol formation from fossil fuel sources contribute majority of summertime organic mass at Bakersfield, J. Geophys. Res.-Atmos., 117, D00V26, doi:10.1029/2012JD018170, 2012.

Liu, X., Jeffries, H. E., and Sexton, K. G.: Hydroxyl radical and ozone initiated photochemical reactions of 1,3-butadiene, Atmos. Environ., 33, 3005-3022, 1999.

Ng, N. L., Kroll, J. H., Keywood, M. D., Bahreini, R. A., Varutbangkul, V., Flagan, R. C., Seinfeld, J. H.: Contribution of firstversus second-generation products to secondary organic aerosols formed in the oxidation of biogenic hydrocarbons, Environ. Sci. Technol., 40, 2283-2297, 2006.

Nguyen, T. B., Roach, P. J., Laskin, J., Laskin, A., and Nizkorodov, S. A.: Effect of humidity on 10 the composition of isoprene photooxidation secondary organic aerosol, Atmos. Chem. Phys., 11, 6931-6944, doi:10.5194/acp-11-6931-2011, 2011.

Nguyen, T. B., Coggon, M. M., Bates, K. H., Zhang, X., Schwantes, R. H., Schilling, K. A., Loza, C. L., Flagan, R. C., Wennberg, P. O., and Seinfeld, J. H.: Organic aerosol formation from the reactive uptake of isoprene epoxydiols (IEPOX) onto non-acidified inorganic seeds, Atmos. Chem. Phys., 14, 3497-3510, 2014, http://www.atmos-chem-phys.net/14/3497/2014/.

Notario, A., Le Bras, G., and Mellouki, A.: Kinetics of $\mathrm{Cl}$ atom reactions with butadienes including isoprene, Chem. Phys. Lett., 281, 421-425, 1997.

Offenberg, J. H., Kleindienst, T. E., Jaoui, M., Lewandowski, M., and Edney, E. O.: Thermal properties of secondary organic aerosols, Geophys. Res. Lett., 33, L03816, doi:10.1029/2005GL024623, 2006.

Pankow, J. F., Luo, W., Tavakoli, A. D., Chen, C., and Isabelle, L. M.: Delivery levels and behavior of 1,3-butadiene, acrylonitrile, benzene, and other toxic volatile organic compounds in mainstream tobacco smoke from two brands of commercial cigarettes, Chem. Res. Toxicol., 17, 805-813, 2004.

Paulot, F., Crounse, J. D., Kjaergaard, H. G., Kürten, A., St. Clair, J. A., Seinfeld, J. H., and Wennberg, P. O.: Unexpected epoxide formation in the gas-phase photooxidation of isoprene, Science, 325, 730-732, 2009.

Penn, A. and Snyder, C. A.: 1,3-Butadiene, a vapor phase component of environmental tobacco smoke, accelerates arteriosclerotic plaque development, Circulation, 93, 552-557, 1996.

Piletic, I. R., Offenberg, J. H., Olson, D. A., Jaoui, M., Krug, J., Lewandowski, M., Turlington, J. M., and Kleindienst, T. E.: Constraining carbonaceous aerosol sources in a receptor model by including ${ }^{14} \mathrm{C}$ data with redox species, organic tracers, and elemental/organic carbon measurements, Atmos. Environ., 80, 216225, 2013.

Pope III, C. A., Ezzati, M., and Dockery, D. W.: Fine-particulate air pollution and life expectancy in the United States, New Engl. J. Med., 360, 376-386, doi:10.1056/NEJMsa0805646, 2009.

Pye, H. O. T., Pinder, R.W., Piletic, I. R., Xie, Y., Capps, S. L., Lin, Y.-H., Surratt, J. D., Zhang, Z., Gold, A., Luecken, D. J., Hutzell, W. T., Jaoui, M., Offenberg, J. H., Kleindienst, T. E., Lewandowski, M., and Edney, E. O.: Epoxide pathways improve 
model predictions of isoprene markers and reveal key role of acidity in aerosol formation, Environ. Sci. Technol., 47, 1105611064, doi:10.1021/es402106h, 2013.

Sato, K.: Detection of nitrooxypolyols in secondary organic aerosol formed from the photooxidation of conjugated dienes under high- $\mathrm{NO}_{\mathrm{x}}$ conditions, Atmos. Environ., 42, 6851-6861, 2008.

Sato, K., Nakao, S., Clark, C. H., Qi, L., and Cocker III, D. R.: Secondary organic aerosol formation from the photooxidation of isoprene, 1,3-butadiene, and 2,3-dimethyl-1,3-butadiene under high $\mathrm{NO}_{\mathrm{x}}$ conditions, Atmos. Chem. Phys., 11, 7301-7317, 2011, http://www.atmos-chem-phys.net/11/7301/2011/.

Sisler, J. F. and Malm, W. C.: The relative importance of soluble aerosols to spatial and seasonal trends of impaired visibility in the United States, Atmos. Environ., 28, 851-862, 1994.

Smith, D. F., Kleindienst, T. E., and Hudgens, E. E.: Improved high-performance liquid chromatographic method for artifactfree measurements of aldehydes in the presence of ozone using 2,4-dinitrophenylhydrazine, J. Chromatogr. A, 483, 431-436, 1989.

Sorsa, M., Peltonen, K., Anderson, D., Demopoulos, N. A., Neumann, H. G., and Osterman-Golkar, S.: Assesment of environmental and occupational exposures to butadiene as a model for risk estimation of petrochemical emissions, Mutagenesis, 11, 917, 1996.

Surratt, J. D., Murphy, S. M., Kroll, J. H., Ng, N. L., Hildebrandt, L., Sorooshian, A., Szmigielski, R., Vermeylen, R., Maenhaut, W., Claeys, M., Flagan, R. C., and Seinfeld, J. H.: Chemical composition of secondary organic aerosol formed from the photooxidation of isoprene, J. Phys. Chem. A, 110, 9665-9690, 2006.

Surratt, J. D., Lewandowski, M., Offenberg, J. H., Jaoui, M., Kleindienst, T. E., Edney, E. O., and Seinfeld, J. H.: Effect of acidity on secondary organic aerosol formation from isoprene, Environ. Sci. Technol., 41, 5363-5369, 2007.

Surratt, J. D., Chan, A. W. H., Eddingsaas, N. C., Chan, M., Loza, C. L., Kwan, A. J., Hersey, S. P., Flagan, R. C., Wennberg, P. O., and Seinfeld, J. H.: Reactive intermediates revealed in secondary organic aerosol formation from isoprene, $\mathrm{P}$. Natl. Acad. Sci. USA, 107, 6640-6645, 2010.

Szmigielski, R., Surratt, J. D., Vermeylen, R., Szmigielska, K., Kroll, J. H., Ng, N. L., Murphy, S. M., Sorooshian, A., Seinfeld, J. H., and Claeys, M.: Characterization of 2-methylglyceric acid oligomers in secondary organic aerosol formed from the photooxidation of isoprene using trimethylsilylation and gas chromatography/ion trap mass spectrometry, J. Mass. Spectrom., 42, 101-116, 2007.

Tanimoto, H. and Akimoto, H.: A new peroxycarboxylic nitric anhydride identified in the atmosphere: $\mathrm{CH}_{2}=\mathrm{CHC}(\mathrm{O}) \mathrm{OONO}_{2}$ (APAN), Geophys. Res. Let., 28, 2831-2834, 2001.
Thornton-Manning, J. R., Dahl, A. R., Bechtold, W. E., Griffith Jr, W. C., and Henderson, R. F.: Comparison of the disposition of butadiene epoxides in Sprague-Dawley rats and B6C3F1 mice following a single and repeated exposures to 1,3-butadiene via inhalation, Toxicology, 123, 125-134, 1997.

United States Environmental Protection Agency (US EPA): Locating and estimating air emissions from sources of 1,3-butadiene, EPA-454/R-96-008, Office of Air Quality Planning and Standards, Research Triangle Park, NC, 1996.

United States Environmental Protection Agency (US EPA): Health assessment of 1,3-butadiene, EPA/600/P-98/001F, Office of Research and Development, Washington, DC, 2002.

Vimal, D., Pacheco, A. B., Iyengar, S. S., and Stevens, P. S.: Experimental and ab initio dynamical investigations of the kinetics and intramolecular energy transfer mechanisms for the $\mathrm{OH}+1,3-$ butadiene reaction between 263 and $423 \mathrm{~K}$ at low pressure, J. Phys. Chem. A, 112, 7227-7237, 2008.

Wang, W., Wu, M. H., Li, L., Zhang, T., Liu, X. D., Feng, J. L., Li, H. J., Wang, Y. J., Sheng, G. Y., Claeys, M., and Fu, J. M.: Polar organic tracers in $\mathrm{PM}_{2.5}$ aerosols from forests in eastern China, Atmos. Chem. Phys., 8, 7507-7518, doi:10.5194/acp-87507-2008, 2008.

Ye, Y., Galbally, I. E., Weeks, I. A., Duffy, B. L., and Nelson, P. F.: Evaporative emissions of 1,3-butadiene from petrol-fuelled motor vehicles, Atmos. Environ., 32, 2685-2692, 1998.

Zhang, H., Surratt, J. D., Lin, Y. H., Bapat, J., and Kamens, R. M.: Effect of relative humidity on SOA formation from isoprene/NO photooxidation: enhancement of 2-methylglyceric acid and its corresponding oligoesters under dry conditions, Atmos. Chem. Phys., 11, 6411-6424, doi:10.5194/acp-11-6411-2011, 2011.

Zhang, Z., Lin, Y. H., Zhang, H., Surratt, J. D., Ball, L. M., and Gold, A.: Technical note: Synthesis of isoprene atmospheric oxidation products: isomeric epoxydiols and the rearrangement products cis- and trans-3-methyl-3,4-dihydroxytetrahydrofuran, Atmos. Chem. Phys., 12, 8529-8535, doi:10.5194/acp-12-8529 2012, 2012.

Zhang, H., Zhang, Z., Cui, T., Lin, Y-H., Bhathela, N. A., Ortega, J., Worton, D. R., Goldstein, A. H., Guenther, A., Jimenez, J. L., Gold, A., and Surratt, J. D.: Secondary organic aerosol formation via 2-methyl-3-buten-2-ol photooxidation: evidence of acid-catalyzed reactive uptake of epoxides, Environ. Sci. Technol. Lett., 1, 242-247, 2014. 